\title{
Autoantibodies to Epilepsy-Related LGI1 in Limbic Encephalitis Neutralize LGI1-ADAM22 Interaction and Reduce Synaptic AMPA Receptors
}

\author{
Toshika Ohkawa, ${ }^{1,2}$ Yuko Fukata, ${ }^{1,2}$ Miwako Yamasaki, ${ }^{3}$ Taisuke Miyazaki, ${ }^{3}$ Norihiko Yokoi, ${ }^{1,2}$ Hiroshi Takashima, ${ }^{4}$ \\ Masahiko Watanabe, ${ }^{3,5}$ Osamu Watanabe, ${ }^{4 *}$ and Masaki Fukata ${ }^{1,2 *}$ \\ ${ }^{1}$ Division of Membrane Physiology, Department of Cell Physiology, National Institute for Physiological Sciences (NIPS), Okazaki 444-8787, Japan; \\ ${ }^{2}$ Department of Physiological Sciences, School of Life Science, The Graduate University for Advanced Studies (SOKENDAI), Okazaki 444-8787, Japan; \\ ${ }^{3}$ Department of Anatomy, Hokkaido University Graduate School of Medicine, Sapporo 060-8638, Japan; ${ }^{4}$ Department of Neurology and Geriatrics, \\ Kagoshima University Graduate School of Medical and Dental Science, Kagoshima 890-8544, Japan; and 5Japan Science and Technology Agency, Core \\ Research for Evolutional Science and Technology, Chiyoda-ku, Tokyo 102-0075, Japan
}

\begin{abstract}
More than 30 mutations in LGI1, a secreted neuronal protein, have been reported with autosomal dominant lateral temporal lobe epilepsy (ADLTE). Although LGI1 haploinsufficiency is thought to cause ADLTE, the underlying molecular mechanism that results in abnormal brain excitability remains mysterious. Here, we focused on a mode of action of LGIl autoantibodies associated with limbic encephalitis (LE), which is one of acquired epileptic disorders characterized by subacute onset of amnesia and seizures. We comprehensively screened human sera from patients with immune-mediated neurological disorders for LGI1 autoantibodies, which also uncovered novel autoantibodies against six cell surface antigens including DCC, DPP10, and ADAM23. Our developed ELISA arrays revealed a specific role for LGI1 antibodies in LE and concomitant involvement of multiple antibodies, including LGI1 antibodies in neuromyotonia, a peripheral nerve disorder. LGI1 antibodies associated with LE specifically inhibited the ligand-receptor interaction between LGI1 and ADAM22/23 by targeting the EPTP repeat domain of LGI1 and reversibly reduced synaptic AMPA receptor clusters in rat hippocampal neurons. Furthermore, we found that disruption of LGI1-ADAM22 interaction by soluble extracellular domain of ADAM22 was sufficient to reduce synaptic AMPA receptors in rat hippocampal neurons and that levels of AMPA receptor were greatly reduced in the hippocampal dentate gyrus in the epileptic LGI1 knock-out mouse. Therefore, either genetic or acquired loss of the LGI1-ADAM22 interaction reduces the AMPA receptor function, causing epileptic disorders. These results suggest that by finely regulating the synaptic AMPA receptors, the LGI1-ADAM22 interaction maintains physiological brain excitability throughout life.
\end{abstract}

\section{Introduction}

Epilepsy is a worldwide and devastating brain disorder that is characterized by recurrent seizures. Most inherited forms of ep-

\footnotetext{
Received Aug. 15, 2013; revised Sept. 23, 2013; accepted 0ct. 9, 2013.

Author contributions: T.O., Y.F., and M.F. designed research;T.O., Y.F., M.Y., T.M., N.Y., H.T.,M.W., O.W., and M.F. performed research; T.O., Y.F., M.Y., T.M., N.Y., H.T., M.W., O.W., and M.F. analyzed data; T.O., Y.F., M.W., and M.F. wrote the paper.

This work was supported by grants from the Ministry of Education, Culture, Sports, Science and Technology (Grants 23110520 and 25110733 to Y.F.; a Comprehensive Brain Science Network grant to M.W.; and Grant 25461286 to 0.W.); the Ministry of Health, Labour and Welfare (Intramural Research Grant [H24-12] to Y.F.; and Grants 24133701 and Research on Measures for Intractable Diseases [H24-017] to 0.W.); and the Cabinet Office (Funding Program for Next Generation World-Leading Researchers Grant LS123 to M.F.). We thank K.L. Lovero and R.A. Nicoll (University of California San Francisco) for helpful discussions; E. Peles (Weizmann Institute) for CASPR2 plasmids; Kazusa DNA Research Institute and Dr. Y. Kubo (NIPS) for DPP10 CDNA; members of the Fukata laboratory and Y. Shirahama for kind support; the physicians for providing serum samples and clinical information from the patients; and all of the patients and their families.

The authors declare no competing financial interests.

This article is freely available online through the J Neurosci Author Open Choice option.

Correspondence should be addressed to Masaki Fukata, MD, PhD, Division of Membrane Physiology, Department of Cell Physiology, National Institute for Physiological Sciences, 5-1 Higashiyama, Myodaiji, Okazaki, Aichi 444-8787,

Japan.E-mail: mfukata@nips.ac.jp or mw90@m3.kufm.kagoshima-u.ac.jp.

* 0 .W. and M.F. contributed equally to this work.

DOI:10.1523/JNEUROSCI.3506-13.2013

Copyright $\odot 2013$ the authors $\quad 0270-6474 / 13 / 3318161-14 \$ 15.00 / 0$
}

ilepsy result from mutations in ion channels that regulate the excitability of neurons directly (Noebels, 2003; Steinlein, 2004). In contrast, LGI1 is a monogenic, human epilepsy-related gene (Gu et al., 2002; Kalachikov et al., 2002; Morante-Redolat et al., 2002) that encodes a secreted neuronal protein (Senechal et al., 2005). Mutations in LGI1 are linked to autosomal dominant lateral temporal lobe epilepsy (ADLTE, also known as autosomal dominant partial epilepsy with auditory features [ADPEAF]), a rare, inherited epileptic syndrome characterized by partial seizures with acoustic or visual hallucinations (Kegel et al., 2013). Many LGI1 mutations reported in ADLTE patients prevent their secretion in cultured cells, suggesting that LGI1 haploinsufficiency is a pathogenic basis for LGI1-mediated ADLTE (Senechal et al., 2005; Fukata et al., 2006; Nobile et al., 2009). Consistent with human genetic evidence, LGI1 homozygous knock-out (KO) mice display repeated generalized seizures and die within 3 weeks after birth (Chabrol et al., 2010; Fukata et al., 2010; Yu et al., 2010). LGI1 heterozygous KO mice exhibit increased susceptibility to seizure-inducing stimuli (Chabrol et al., 2010; Fukata et al., 2010).

Despite definitive genetic evidence, the pathophysiological function of LGI1 in the brain remains controversial. So far, three 
Table 1. Clinical features in 145 patients tested in this study

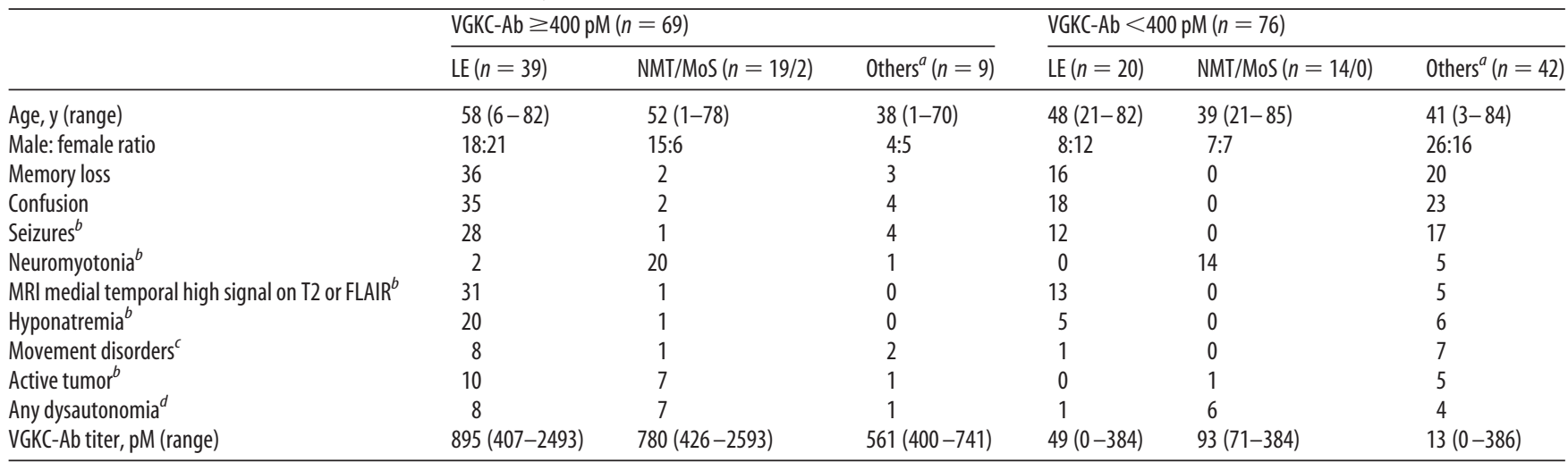

The data represent the number or median (range).

${ }^{a}$ For a description of the patients in the Others category; see Materials and Methods.

${ }^{b}$ Data were available for 144 patients.

'Data were available for 124 patients.

${ }^{d}$ Data available for 130 patients.

molecular functions of LGI1 have been proposed: (1) LGI1 prevents the inactivation of the Kv1 voltage-gated potassium channels (VGKC) through the cytoplasmic regulatory protein $\mathrm{Kv} \beta$ (Schulte et al., 2006); (2) LGI1 regulates the neuronal development of glutamatergic circuits in the hippocampus (Zhou et al., 2009); and (3) LGI1 interacts with the epilepsy-related ADAM22/23 transmembrane proteins and regulates AMPA receptor (AMPAR)-mediated synaptic transmission in the hippocampus (Fukata et al., 2006; Fukata et al., 2010).

The pivotal role of LGI1 in epileptic disorders was further expanded with the recent discovery of LGI1 autoantibodies in patients with autoimmune limbic encephalitis (LE), which is characterized by amnesia and seizures (Irani et al., 2010; Lai et al., 2010). LGI1 antibodies were also detected in immune-mediated peripheral nerve disorders, neuromyotonia (NMT: characterized by peripheral nerve hyperexcitability), and Morvan syndrome (MoS: characterized by peripheral nerve hyperexcitability with neuropsychiatric features; Irani et al., 2010; Irani et al., 2012). Although autoimmune synaptic disorders, including LE, are thought to involve autoantibody-induced dysfunction of target ion channels, such as NMDA receptor (NMDAR; Dalmau et al., 2008; Hughes et al., 2010) and AMPAR (Lai et al., 2009), the mode of action of LGI1 antibodies remains unknown.

Here, we aimed to clarify a pathogenic role and a mode of action of LGI1 antibodies in LE. We demonstrate that LGI1 antibodies play an exclusive role in the pathogenesis of LE and disrupt the ligand-receptor interaction of LGI1 with ADAM22 or ADAM23, resulting in reversible reduction in synaptic AMPARs. This study establishes a direct biological role of LGI1 antibodies in causing LE and highlights the importance of the LGI1ADAM22 interaction in regulating brain excitability and probably memory storage.

\section{Materials and Methods}

The experiments using human sera were reviewed and approved by ethic committees at NIPS and Kagoshima University, and written informed consent was obtained from all patients or their family members. All animal studies were reviewed and approved by the ethic committees at NIPS and Hokkaido University and were performed according to the institutional guidelines concerning the care and handling of experimental animals.

Study population. In this study, 1199 serum samples were collected from patients who were diagnosed with or suspected of immunemediated disorders of the CNS or peripheral nervous system. These pa- tients were seen by the authors or by clinicians at other institutions (from 72 centers in Japan) between January 4, 2006 and December 25, 2011. Diagnoses were categorized into three groups: LE, NMT/MoS, and other neurological disorders that may have autoimmune etiology (Others). To obtain serum samples with LGI1 autoantibodies (Irani et al., 2010; Lai et al., 2010), sera were tested for the presence of VGKC-complex antibodies and categorized into two groups as described previously (Kleopa et al., 2006; Irani et al., 2010): positive (titers $\geq 400 \mathrm{pM}$ ) or negative (titers $<400$ pM). All VGKC-complex antibody-positive (69 cases including 39 LE, 19 NMT, $2 \mathrm{MoS}$, and 9 Others) samples were selected (Table 1 ). In addition, 76 patients of the VGKC-complex antibody-negative group were randomly selected (20 LE, 14 NMT, and 42 Others) because the VGKCcomplex antibody-negative group may still have known (such as LGI1) or unknown autoantibodies. Then, serum samples from a total of 145 patients ( 78 males and 67 females) with LE $(n=59)$, NMT $(n=33)$, MoS $(n=2)$, and Others $(n=51)$ were sent to NIPS via Kagoshima University and analyzed (further detailed information on 145 patients tested in this study is summarized in Table 1). Patients categorized into the Others category who were positive for VGKC-complex antibodies included those with intractable epilepsy $(n=2)$, Hashimoto's encephalopathy $(n=2)$, cramp-fasciculation syndrome $(n=1)$, encephalopathy $(n=1)$, encephalitis $(n=1)$, NMDAR encephalitis $(n=1)$, and myasthenia gravis (MG; $n=1)$. Patients categorized into the Others category who were negative for VGKC-complex antibodies included those with encephalitis $(n=16)$, encephalopathy $(n=7)$, cramp-fasciculation syndrome $(n=5)$, NMDAR encephalitis $(n=3)$, epilepsy $(n=3)$, meningitis $(n=3), \mathrm{MG}(n=1)$, medial temporal sclerosis $(n=2)$, Hashimoto's encephalopathy $(n=1)$, and stiff-person syndrome $(n=$ $1)$. For the cell-based binding assay and ELISA testing, we also used serum samples from 22 patients with neurodegenerative diseases as controls (10 males and 12 females) because they were diagnosed during the same study period and autoimmunity has not been linked to the incidence of neurodegenerative diseases. These control diseases included amyotrophic lateral sclerosis $(n=7)$, spinocerebellar degeneration $(n=$ $6)$, multiple system atrophy $(n=5)$, Parkinson's disease $(n=2)$, corticobasal degeneration $(n=1)$, and frontotemporal lobar degeneration $(n=1)$. Because 2 of 22 patients with neurodegenerative diseases were positive for Deleted in colorectal carcinoma (DCC) ELISA, we tested 23 healthy individuals (age 24-46) as additional controls (12 males and 11 females).

Antibodies. The antibodies used in this study included: rabbit polyclonal antibodies to GluA1 (extracellular epitope, PC246; Calbiochem), GluA1 (Yamazaki et al., 2010), LGI1 (ab30868; Abcam), ADAM22 (ab56118; Abcam), HA (Y-11; Santa Cruz Biotechnology), HA (561; MBL), and Prox1 (ab11941; Abcam); two guinea pig polyclonal antibodies to vGluT1 (for Fig. 6: AB5905, Millipore and for Fig. 7, see Miyazaki et al., 2003); mouse monoclonal antibodies to DCC (ab16793; Abcam), 
A

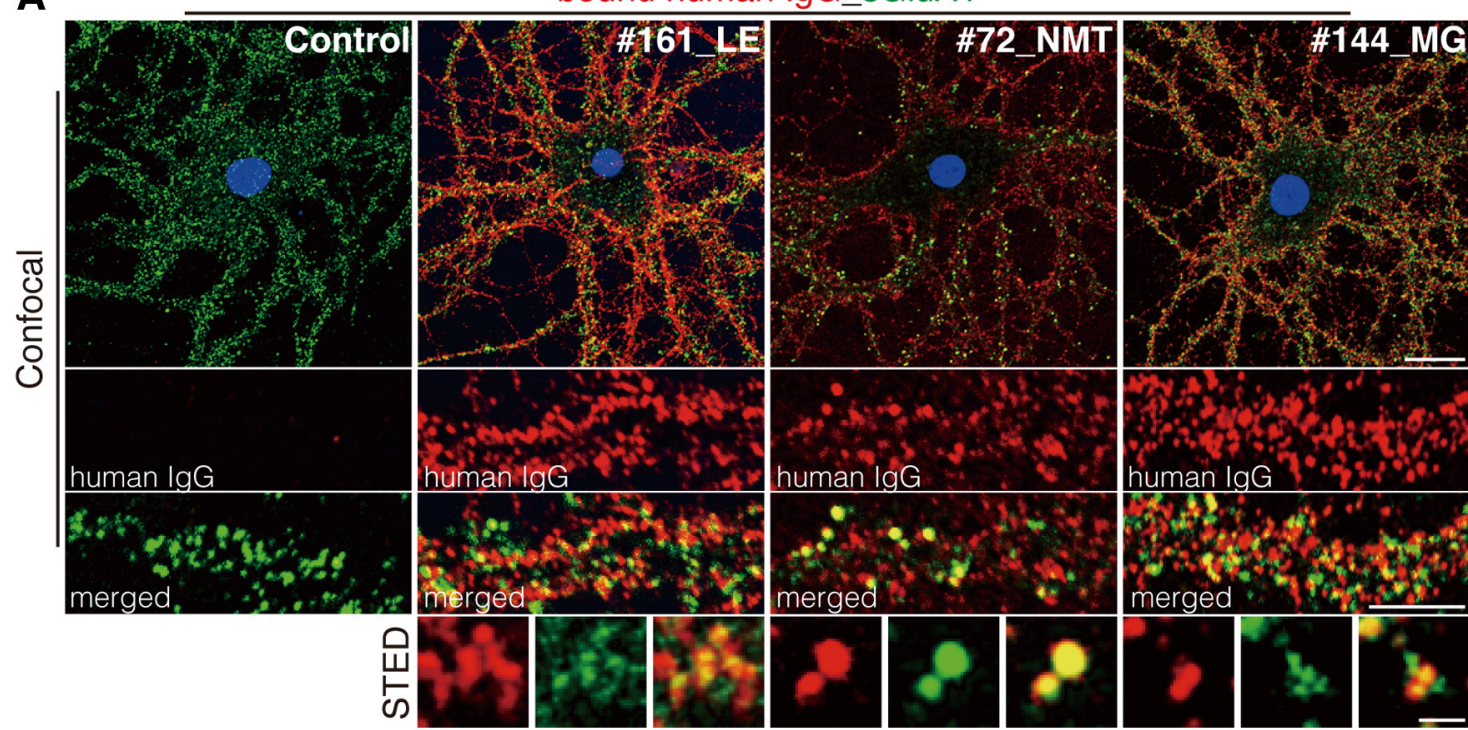

B

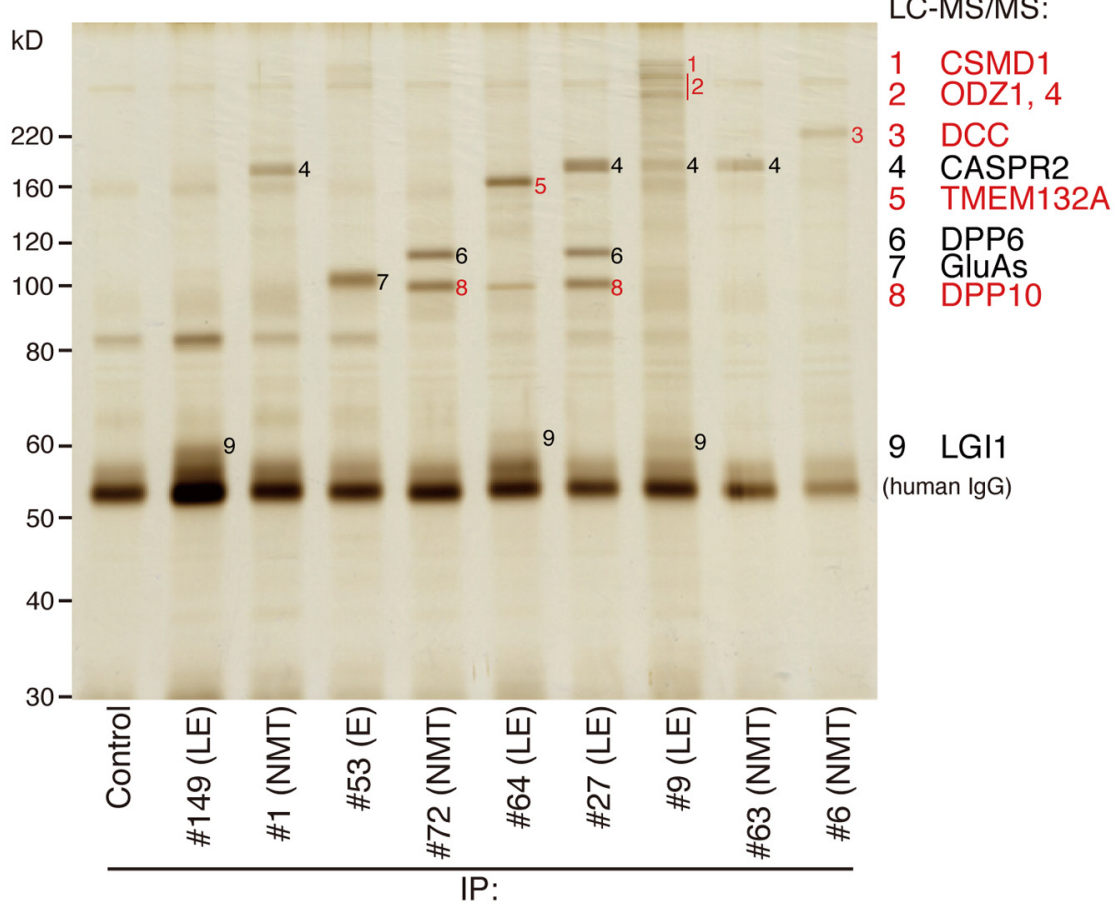

Figure 1. Systematic identification of cell surface autoantigens targeted in neuroimmunological disorders. A, Differential reactivity of serum antibodies to hippocampal neurons. We screened the sera from patients that strongly bind to the neuronal cell surface. Live rat hippocampal neurons were incubated with the individual sera (1:100 dilution) and an antibody to the extracellular epitope of GluA1. Surface GluA1 (sGluA1, green) and bound human IgG (red) were visualized by confocal or STED microscopy. Representative serum results are shown. Subsequent experiments revealed that sera \#161, \#72, and \#144 included LGI1, DPP10, and DCC antibodies, respectively. Scale bars, $20 \mu \mathrm{m}$ (top); $5 \mu \mathrm{m}$ (middle); and $0.5 \mu \mathrm{m}$ (bottom). B, Isolation of autoantibody-mediated immune complexes from cultured hippocampal neurons. Live rat hippocampal neurons were incubated with the indicated sera (1:50 dilution). Isolated immune complexes were separated by SDS-PAGE, followed by silver staining. Specific protein bands were analyzed by the LC-MS/MS for protein identification (protein name: black, known antigens; red, novel antigen candidates). Representative serum results are shown. E, encephalitis; and IP, immunoprecipitation.

PSD-95 (MA1-046; Thermo Fisher Scientific), FLAG (M2; SigmaAldrich), and GAD67 (1G10.2; Millipore); and a rat monoclonal antibody to FLAG (NBP1-06712; Novus Biologicals). Rabbit polyclonal antibodies to ADAM22 were raised against GST-ADAM22-C1 (aa 757857) for the immunoprecipitation and GST-ADAM22-C2 (aa 858-898) for the immunofluorescence analysis. A rabbit polyclonal antibody to ADAM23 was raised against GST-ADAM23 (aa 815-829). These antibodies were affinity purified on a CNBr-activated Sepharose 4B (GE Healthcare) column containing an immunizing antigen.

Plasmid construction. The cDNA of rat transmembrane protein $132 \mathrm{~A}$ (TMEM132A; NM_178021) was cloned from rat brain total RNA by
RT-PCR. cDNAs of human DCC (pFIKE0067) and human Netrin-1 (IOH81706) were purchased from Promega and Invitrogen, respectively. Human odd Oz/ten-m homolog 1 (ODZ1; BC140783) and human Cub and sushi multiple domains 1 (CSMD1; BC156304) cDNAs were purchased from Thermo Fisher Scientific. Human dipeptidyl-peptidase 10 (DPP10; KIAA1492) cDNA was provided by the Kazusa DNA Research Institute (Chiba, Japan) and Dr. Yoshihiro Kubo (NIPS). These cDNAs were subcloned into pCAGGS vector and tagged with HA or FLAG. To construct pcDNA3.1:LGIs-FLAG-GPI, the glycosylphosphatidylinositol (GPI) sequence (91-116 aa) of mouse Lynx1 (NM_011838) was added to the $\mathrm{C}$ terminus of rat LGIs-FLAG (Fukata et al., 2006; Fukata et al., 2010). 
A

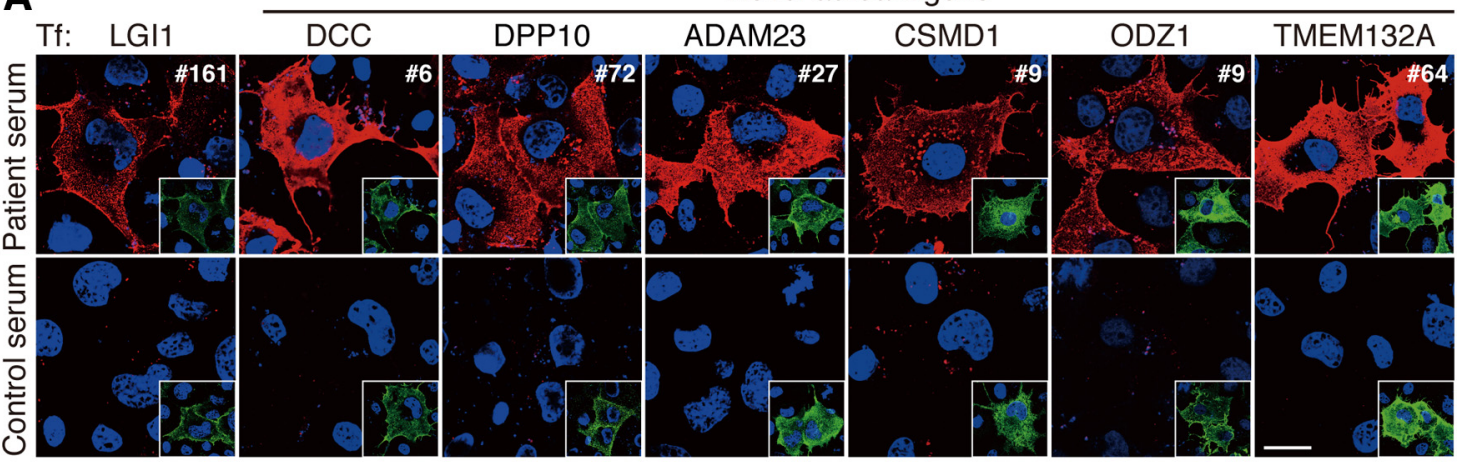

B

Surface-expressed

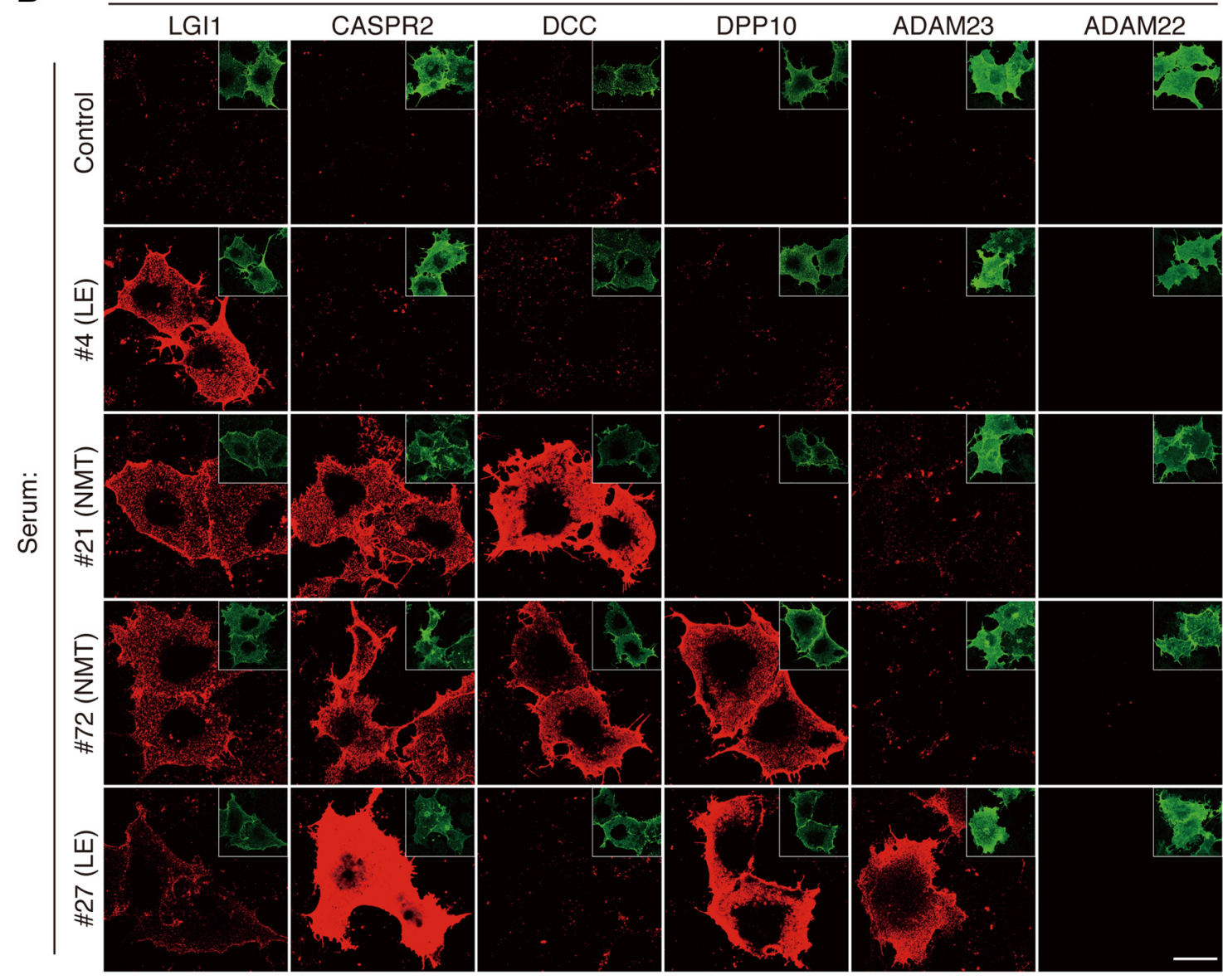

Figure 2. Determination of novel autoantigens by the cell-based binding assay. A, COS7 cells were transfected (Tf) to surface-express the indicated antigens. Transfected cells were fixed and doubly stained with the patient serum (1:10 dilution; bound human lgG, red) together with the antibody to surface-expressed antigen (green in insets). Nuclear DNA was stained by Hoechst 33342 (blue) to distinguish untransfected cells. Representative serum results are shown. $\boldsymbol{B}$, Multiple cell surface proteins are targeted in some patients. The indicated sera from patients were examined for binding to surface-expressed antigen panels of LGI1-, CASPR2-, DCC-, DPP10-, ADAM23-, and ADAM22-expressing COS7 cells (bound human IgG, red; surface-expressed antigens, green in insets). None of the sera showed binding to ADAM22. Scale bars, $20 \mu \mathrm{m}$.

To generate the chimeric constructs LRR1-EPTP3 and LRR3-EPTP1, either LRR1 corresponding to 1-223 aa of LGI1 and EPTP3 (221-548 aa of LGI3) or LRR3 (1-220 aa of LGI3) and EPTP1 (224-557 aa of LGI1) were fused by PCR, respectively. To generate soluble forms of ADAM22ex and ADAM23ex, the extracellular domains of mouse ADAM22ex (32-727 aa) and mouse ADAM23ex (57-787 aa) were C-terminally tagged with an HA- or Hisx6-epitope and subcloned into pAP5 vector (GenHunter). All PCR products were analyzed by DNA sequencing (Functional genomics facility, National Institute for Basic Biology, Japan). Dr. Elior Peles (Weizmann Institute, Rehovot, Israel) kindly provided pCi-neo:CASPR2-HA (Poliak et al., 1999). The other
LGIs and ADAMs constructs were described previously (Fukata et al., 2006; Fukata et al., 2010).

Immunofluorescence analysis of cultured hippocampal neurons. Cultured rat hippocampal neurons $\left(5 \times 10^{4}\right.$ cells $)$ were obtained from E18-19 embryos and seeded onto $12 \mathrm{~mm}$ coverslips in 24 well dishes. Live neurons (21-28 DIV) were incubated with the patient serum (diluted 1:100) together with the GluA1 antibody to the extracellular epitope of GluA1 for $1 \mathrm{~h}$ at $37^{\circ} \mathrm{C}$. GluA1 staining was performed as an internal positive control. The neurons were subsequently fixed with $4 \%$ paraformaldehyde/120 mM sucrose/100 mM HEPES, pH 7.4, at room temperature for $10 \mathrm{~min}$ and blocked with PBS containing $10 \mathrm{mg} / \mathrm{ml} \mathrm{BSA}$ 
for $15 \mathrm{~min}$ on ice. The bound human IgG and surface GluAl were visualized using Cy3-conjugated and Alexa Fluor 488-conjugated secondary antibodies, respectively. Fluorescent images were captured with a confocal laser scanning microscopy system (LSM5 Exciter; Carl Zeiss) equipped with a Plan Apochromat 63×/1.40 numerical aperture (NA) oil-immersion objective lens. For stimulated emission depletion microscopy (STED) observation, live-labeled neurons were visualized with DyLight488-conjugated and ATTO425-conjugated secondary antibodies. The images were acquired with TCS STED CW (Leica Microsystems) and the data were treated by STED deconvolusion software (LAS AF; Leica).

For Figure 8, $M$ and $N$, live neurons (19 DIV) were incubated with the patient serum (\#161, diluted 1:200) for $1 \mathrm{~h}$ at $37^{\circ} \mathrm{C}$ for the surface LGI1 staining. The neurons were then fixed with methanol for $10 \mathrm{~min}$ at $-30^{\circ} \mathrm{C}$ and blocked with PBS containing $10 \mathrm{mg} / \mathrm{ml} \mathrm{BSA}$ for $20 \mathrm{~min}$ on ice. The bound human IgG was visualized using Alexa Fluor 647conjugated secondary antibody. The neurons were subsequently incubated with anti-GAD67 and anti-ADAM22 (or anti-ADAM23) antibodies and stained by Cy3-conjugated and Alexa Fluor 488conjugated secondary antibodies, respectively. Fluorescent images were captured with a confocal laser scanning microscopy system (TCS SP5 II; Leica) equipped with a HCX PL APO $63 \times / 1.40$ NA oil-immersion objective lens combining with the Leica HyD detectors. The specificity of ADAM22 and ADAM23 antibodies was confirmed by using their KO mice (N. Yokoi, Y. Fukata, D. Meijer, M. Watanabe, and M. Fukata, unpublished observations).

Immunoprecipitation and mass spectrometry. Cultured rat hippocampal neurons $\left(5 \times 10^{5}\right.$ cells/well) were seeded in 6 well plates ( 3 wells/ immunoprecipitation). The neurons were incubated with the patient serum (diluted 1:50) for $1 \mathrm{~h}$ at $37^{\circ} \mathrm{C}$. The neurons were subsequently washed twice with PBS and then lysed with buffer A ( $20 \mathrm{~mm}$ Tris- $\mathrm{HCl}, \mathrm{pH}$ 8.0, $1 \mathrm{~mm}$ EDTA, $100 \mathrm{~mm} \mathrm{NaCl}, 1.3 \%$ Triton X-100, and $50 \mu \mathrm{g} / \mathrm{ml}$ PMSF). The lysates were cleared by centrifugation at $10,000 \times g$ for $5 \mathrm{~min}$ at $4{ }^{\circ} \mathrm{C}$. The immune complexes were precipitated with Protein A Sepharose (GE Healthcare). The immunoprecipitates were separated by SDSPAGE, and the gels were subsequently analyzed by silver staining and Western blotting (data not shown). All specific protein bands were excised from a silver-stained gel and analyzed with mass spectrometry as described previously (Fukata et al., 2010). The gel pieces with the corresponding molecular weights in the control serum sample were also analyzed to rule out nonspecific binding of human serum antibodies.

Cell-based binding assay. COS7 cells were seeded onto three poly-Dlysine coated $12 \mathrm{~mm}$ coverslips in each well of a 6 well plate $\left(3 \times 10^{5}\right.$ cells/well) and transfected with the indicated target candidates, including LGI1, CASPR2, ADAM23, DCC, DPP10, TMEM132A, ODZ1, and CSMD1. To display LGI1 on the cell surface, a GPI anchor signal was added to the $\mathrm{C}$ terminus of LGI1. At $24 \mathrm{~h}$ after transfection, the cells were fixed with $2 \%$ paraformaldehyde at room temperature for $20 \mathrm{~min}$ and blocked with PBS containing $10 \mathrm{mg} / \mathrm{ml}$ BSA for $10 \mathrm{~min}$ on ice. The fixed cells were incubated with the patient serum (diluted 1:10) and anti-FLAG antibody for LGI1, anti-HA antibody for DPP10 and DPP6, or anti-DCC antibody at room temperature for $1 \mathrm{~h}$. This incubation was followed by incubation with the Cy3-conjugated secondary antibody for human serum antibodies and the Alexa Fluor 488-conjugated secondary antibody for the individual target staining. For CASPR2, ADAM23, and TMEM132A with the internal HA tag, after staining surface-bound human IgG, the cells were permeabilized with $0.1 \%$ Triton X-100 for 10 min, blocked with PBS containing $10 \mathrm{mg} / \mathrm{ml} \mathrm{BSA}$, and incubated with the anti-HA polyclonal antibody, followed by staining with the Alexa Fluor 488-conjugated secondary antibody. We confirmed that sera from patients did not bind to untransfected cells that did not express the candidate protein through distinguishing untransfected cells with Hoechst dye (33342; Invitrogen) nucleic acid staining and that neither patient nor control sera bound to COS7 cells that had not been treated with lipofectamine transfection reagent (data not shown). In addition, we confirmed that control sera from patients of neurodegenerative diseases did not bind to the candidate-antigen expressing cells (except for DCC-expressing cells).

Cell-based ELISA. HEK293T cells were plated onto 96 well plates $\left(3 \times 10^{4}\right.$ cells/well; Nunclon TC; Nunc) coated with polyethylenimine. Plasmids (0.1 $\mu \mathrm{g} /$ well for LGI1 and CASPR2, $0.06 \mu \mathrm{g} /$ well for DCC, and $0.08 \mu \mathrm{g} /$ well for
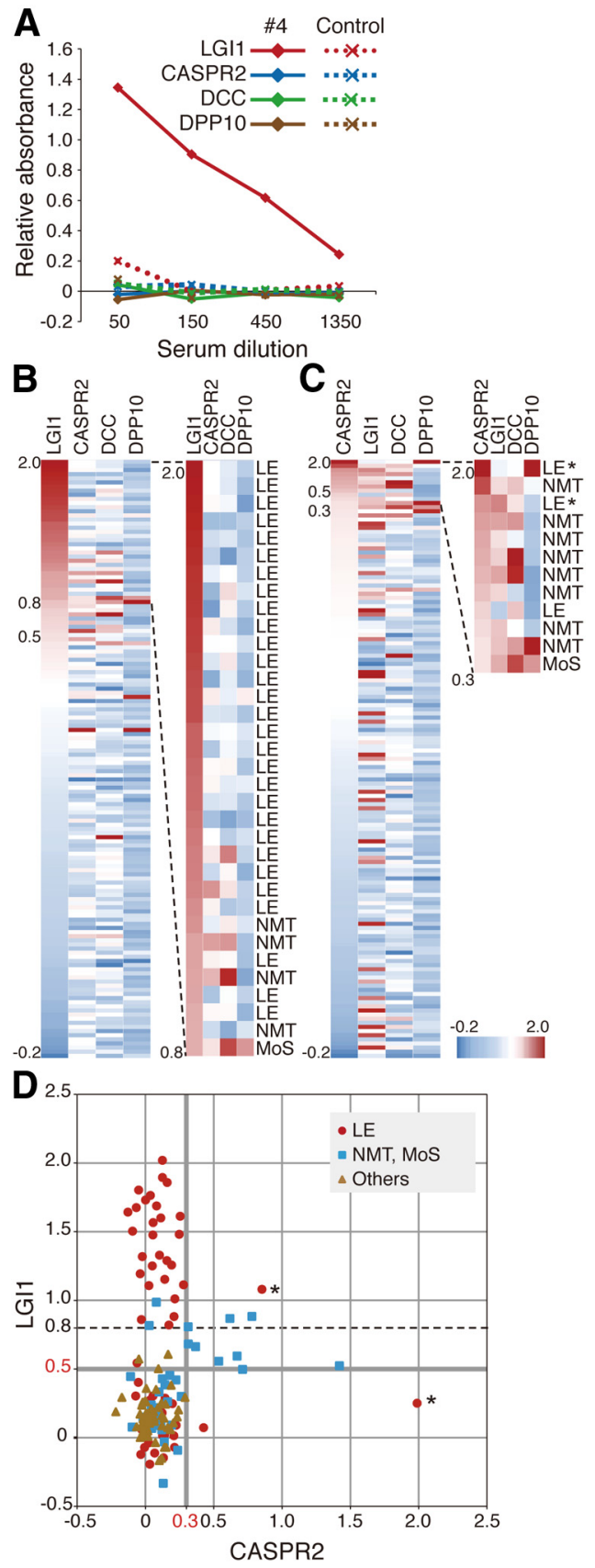

Figure 3. Multiple cell-based ELISA testing reveals an exclusive role for LGI1 antibodies in LE. $A$, Cell-based ELISA tests against LGI1, CASPR2, DCC, and DPP10 show the adequate signal-to-noise ratio. A representative serum \#4 (patient with $L E$ ) showed positive reactivity only to LGI1, but not to CASPR2, DCC, or DPP10. We confirmed a linear relationship between the relative absorbance and the serum dilution factor (1:50-1:1350 dilution) in all sera tested. The control serum tested showed no significant binding to any antigens (dashed lines). The relative absorbance at a dilution of 1:50 was used as the antibody value for an individual patient. $\boldsymbol{B}, \boldsymbol{C}$, LGI1 antibodies occur in LE independently from other antibodies. Heat maps were generated from datasets of all the patients (145 patients). The individual data of the patient serum for LGI1-CASPR2-DCC-DPP10 ELISA $(\boldsymbol{B})$ or CASPR2-LGI1-DCC-DPP10 ELISA (C) are shown in the horizontal columns and are sorted in descending order of the anti-LGI1 (B) or anti-CASPR2 (C) values $(-0.2$ to 2.0). The top groups with high LGI1-ELISA $(>0.8 ; \boldsymbol{B})$ and with high CASPR2-ELISA $(>0.3 ; \boldsymbol{C})$ values are shown in magnified views with the individual diagnosis (LE, NMT, or MoS). D, Scatterplot showing the relationship between LGI1 and CASPR2 antibody values in patients with LE (red circles), NMT (blue squares), or 0thers (brown triangles). Asterisks indicate the cases in which the patients were originally diagnosed with LE but experienced NMT symptoms ( $\# 9$ and \#27, revealed by retrospective examination; $($ and $\boldsymbol{D}$ ). 
Table 2. Relationship between clinical features and autoantibodies to LGI1, CASPR2, DCC, and DPP10

\begin{tabular}{|c|c|c|c|c|c|c|c|c|c|c|c|}
\hline & \multirow[b]{2}{*}{ Total $(N=145)$} & \multicolumn{2}{|c|}{ LGI1 >0.8 } & \multicolumn{2}{|c|}{ LGl1 alone $>0.8$} & \multicolumn{2}{|c|}{ CASPR2 $>0.3$} & \multicolumn{2}{|c|}{$\mathrm{DCC}>0.3$} & \multicolumn{2}{|c|}{ DPP10 $>0.4$} \\
\hline & & $n=34$ & $p^{a}$ & $n=28$ & $p^{a}$ & $n=12$ & $p^{a}$ & $n=12$ & $p^{a}$ & $n=5$ & $p^{a}$ \\
\hline \multicolumn{12}{|l|}{ Clinical features } \\
\hline Memory loss & 77 & 27 & 0.0004 & 23 & 0.0006 & 4 & NS & 5 & NS & 3 & NS \\
\hline Confusion & 82 & 26 & 0.0106 & 22 & 0.0187 & 4 & NS & 5 & NS & 3 & NS \\
\hline Seizures $^{b}$ & 62 & 22 & 0.0052 & 21 & 0.0002 & 2 & NS & 1 & NS & 1 & NS \\
\hline Neuromyotonia $^{b}$ & 42 & 6 & NS & 2 & NS & 11 & $<0.0001$ & 7 & 0.0404 & 4 & 0.0255 \\
\hline Thymoma $^{b}$ & 18 & 8 & 0.0372 & 3 & NS & 10 & $<0.0001$ & 10 & $<0.0001$ & 4 & 0.0008 \\
\hline Myasthenia gravis & 5 & 1 & NS & 0 & NS & 3 & 0.004 & 5 & $<0.0001$ & 2 & 0.0092 \\
\hline Any dysautonomiac & 27 & 6 & NS & 4 & NS & 6 & 0.0178 & 5 & NS & 3 & NS \\
\hline VGKC-Ab $\geq 400 \mathrm{pm}$ & 69 & 32 & $<0.0001$ & 26 & $<0.0001$ & 11 & 0.0016 & 11 & 0.0016 & 4 & NS \\
\hline \multicolumn{12}{|l|}{ Diagnosis } \\
\hline LE & 59 & 29 & $<0.0001$ & 26 & $<0.0001$ & 3 & NS & 4 & NS & 1 & NS \\
\hline NMT/MoS & 35 & 5 & NS & 2 & NS & 9 & $<0.0001$ & 7 & 0.0086 & 3 & NS \\
\hline 0thers & 51 & 0 & NS & 0 & NS & 0 & NS & 1 (MG) & NS & $1(\mathrm{E})$ & NS \\
\hline
\end{tabular}

Numbers indicate frequency based on the ELISA. E, encephalitis; and NS, not significant.

${ }^{a}$ The association between individual autoantibodies and particular clinical features or diagnoses of patients was analyzed with Fisher's exact test.

${ }^{b}$ Data were available for 144 patients.

'Data were available for 130 patients.

DPP10) were transfected into HEK293T cells using Lipofectamine and Plus reagent (Invitrogen). After a $24 \mathrm{~h}$ incubation, the cells were treated with the serially diluted sera from patients (Fig. $3 A$ ) and control subjects together in the same 96 well plate for $15 \mathrm{~min}$ at $37^{\circ} \mathrm{C}$. The cells were washed with PBS and fixed in $4 \%$ paraformaldehyde for $15 \mathrm{~min}$. The cells were then washed once with PBS, twice with PBST (PBS containing 0.05\% Tween 20), and blocked using Protein-Free T20 blocking buffer (Thermo Fisher Scientific) at room temperature for $1 \mathrm{~h}$. Subsequently, the cells were incubated with an HRPconjugated anti-human IgG antibody in a 1:2000 dilution for 15 min at $37^{\circ} \mathrm{C}$ and washed twice with PBST and once with PBS. The cell-bound human IgG was detected using Ultra-TMB substrate solution (Thermo Fisher Scientific). The colorimetric reaction was stopped upon the addition of $2 \mathrm{M}$ sulfuric acid and the resulting plates were measured at $450 \mathrm{~nm}$ absorption with MULTISKAN FC microplate reader (Thermo Fisher Scientific). Wells containing nontransfected cells were used to subtract the background signals. We assessed the quality of the ELISA by calculating the $Z$-prime factors (Zhang et al., 1999). The $Z$-prime factors of the LGI1, CASPR2, DCC, and DPP10 ELISAs were $0.88,0.77,0.61$, and 0.67 , respectively; therefore, the individual ELISA tests were considered to be excellent assays ( $Z$-prime factor $>0.5$ ). The cutoff value, which discriminates the positive results from the negative results, was determined by collating with our cell-based binding assay results. Samples were regarded as positive if their values of ELISA were $>0.5,0.3,0.3$, and 0.4 for LGI1, CASPR2, DCC, and DPP10, respectively. Laboratory investigators performed all of the procedures of ELISA test without knowing clinical features and diagnoses of samples. We used the absolute ELISA values of serum samples as predictor variables and clinical features and diagnoses of patients as outcomes. We categorized clinical features and diagnoses of patients into eight and three groups, respectively, and examined the association of ELISA results (positive or negative) with them (Table 2). The ELISA test for LGI1 should be useful for the clinical diagnosis of autoimmune-mediated LE with a high specificity (94.2\%), sensitivity $(49.2 \%)$, and positive predictive value $(85.3 \%)$ at the 0.8 cutoff point. In addition, the $\chi^{2}$ test showed a significant difference in the frequencies of LE between patients with the LGI1 antibody (cutoff value, 0.8 ) and all 145 patients $(p=1.19 \mathrm{E}-07)$.

Tests of inhibitory effects of LGI1 autoantibodies. To prepare the recombinant soluble form of ADAM22ex-HA or ADAM23ex-HA, at $24 \mathrm{~h}$ after transfection, HEK293T cells were further cultured in serum-free DMEM for $3 \mathrm{~d}$ to mediate the secretion of recombinant proteins into the medium. Subsequently, the conditioned medium was collected and used as soluble ADAM22ex or ADAM23ex. COS7 cells were transfected with LGI1-FLAG-GPI to display LGI1-FLAG on the cell surface. At $24 \mathrm{~h}$ after transfection, the cells were incubated with either control serum or patient serum containing LGI1 antibodies for $10 \mathrm{~min}$ at $37^{\circ} \mathrm{C}(1: 1$ diluted in DMEM). After washing, soluble ADAM22ex-HA or ADAM23ex-HA (3 nM) was applied and the cells were incubated for $1 \mathrm{~h}$ at $4^{\circ} \mathrm{C}$. The cells were washed and fixed with $2 \%$ paraformaldehyde. The bound ADAMex-HA and surface-expressed LGI1-FLAG-GPI were visualized with anti-HA and anti-FLAG antibodies, followed by staining with Alexa Fluor 488- and Alexa Fluor 647-conjugated secondary antibodies, respectively. In addition, the bound serum antibodies were visualized by the Cy3conjugated secondary antibody. Fluorescent images were taken with a confocal laser microscopy system. A similar experiment was performed using secreted Netrin-1-FLAG and DCC for Figure 4, $C$ and $D$. To quantify the intensity of surface ADAM22ex-HA and LGI1-FLAG expression, we randomly chose 15 cells from three independent experiments and measured the mean intensities. The ratio of the ADAM22ex-HA intensity to LGI1-FLAG-GPI intensity was graphed.

To examine the effect of LGIl antibodies in neurons, rat cultured hippocampal neurons (12 DIV) were treated with disease control serum (control \#19) or the serum from an LE patient (\#161) for $3 \mathrm{~d}$. Ten microliters of fresh serum was added daily to $500 \mu$ l of each culture medium (final 6\% concentration). Subsequently, ADAM22 was immunoprecipitated by ADAM22 antibody (targeting ADAM22 cytoplasmic tail)conjugated beads. M-280 Tosylactivated Dynabeads (Invitrogen) were used for antibody conjugation according to manufacturer's instructions. The isolated immune complex was separated by SDS-PAGE and analyzed by Western blotting with anti-ADAM22 and anti-LGI1 antibodies. For the quantification, ImageJ software was used.

To examine the effect of LGI1 antibodies (or soluble form of ADAM22, ADAM22ex-HA) on synaptic AMPARs, cultured hippocampal neurons (12 DIV) were treated with disease control serum (control $\# 19)$, the serum from an LE patient (\#161) or ADAM22ex-HA $(\sim 200$ $\mathrm{nm}$ ) for $3 \mathrm{~d}$, as described above. To examine the reversibility of the inhibitory effect of LGI1 antibodies on synaptic AMPARs, the serumcontaining medium was replaced with serum-free medium after the $3 \mathrm{~d}$ incubation and neurons were further incubated for $24 \mathrm{~h}$. Subsequently, live neurons were incubated with a GluAl antibody for $15 \mathrm{~min}$ at $37^{\circ} \mathrm{C}$. After fixation, the surface-expressed GluA1 was visualized with the Cy3conjugated antibody. The neurons were then permeabilized with $0.1 \%$ Triton X-100 for $10 \mathrm{~min}$, blocked with PBS containing $10 \mathrm{mg} / \mathrm{ml} \mathrm{BSA}$, and incubated with anti-PSD-95 and anti-vGluT1 antibodies, followed by staining with Alexa Fluor 488-conjugated and Alexa Fluor 647conjugated secondary antibodies, respectively. To quantify the synaptic expression of AMPARs, we randomly chose 36 dendrites (20 $\mu \mathrm{m}$ length) from three independent neuronal cultures and analyzed the number and intensity of GluA1 clusters. Synaptic GluA1 puncta, which were adjacent to both vGluT1 and PSD-95 and bigger than $1 / \pi \mu \mathrm{m}$ in diameter (threshold was set at 70 arbitrary units of mean fluorescent intensity), were counted. The quantification of PSD-95 puncta apposed to vGluT1 was analyzed by the same criteria. Microscope control and all image analysis were performed with Carl Zeiss ZEN software.

Immunohistochemistry. For Figure $6 A$, brains of LGI1 KO (LGI1 ${ }^{-1-}$; postnatal day 18 [P18]) mice (Fukata et al., 2010) and their littermate con- 
A


B

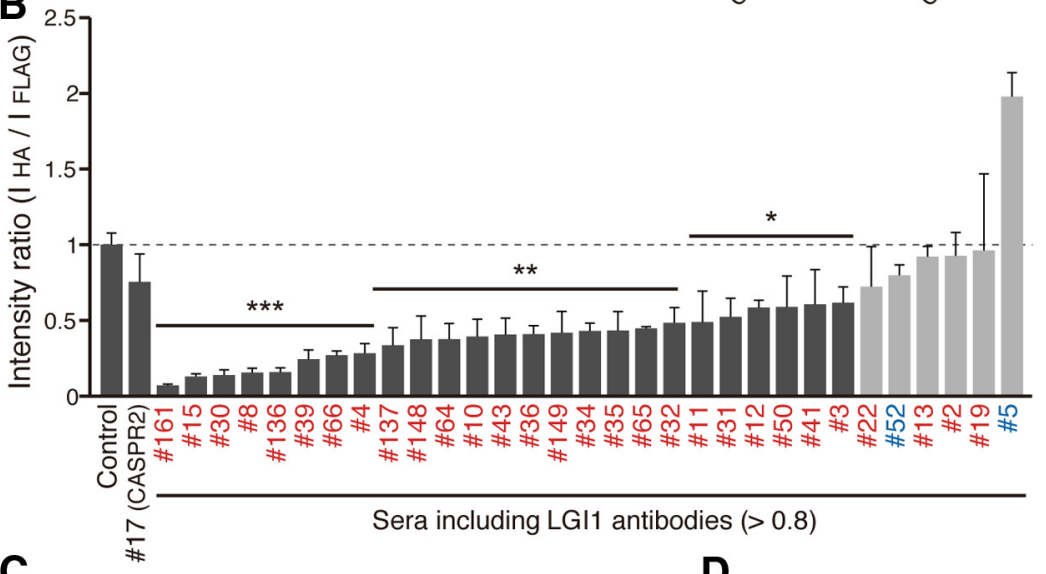

C

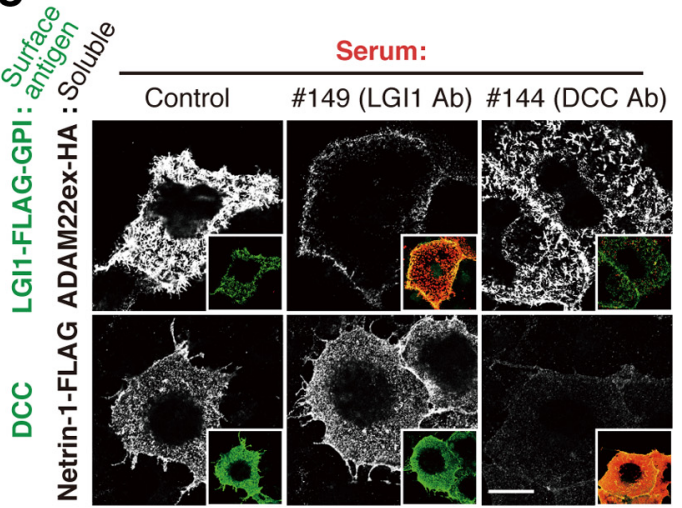

D

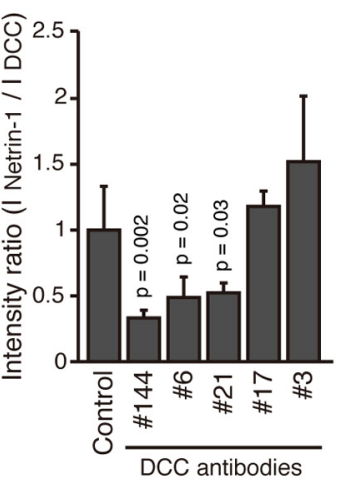

E

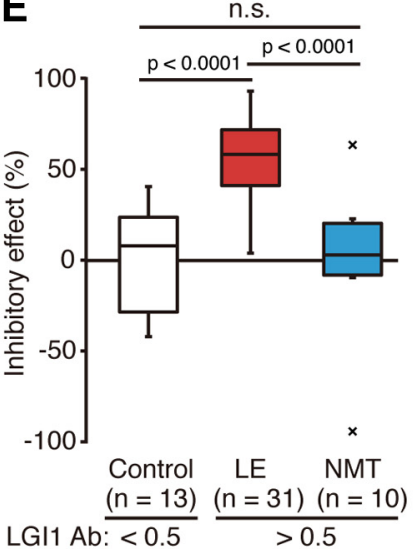

Figure 4. LGI1 autoantibodies associated with LE inhibit the interaction of LGI1 with ADAM22. A, B, COS7 cells transfected with LGI1-FLAG-GPI were incubated with patient or control sera, and then the soluble form of ADAM22 or ADAM23 (ADAMex-HA) was added. Bound ADAM22ex-HA (green), surface-expressed LGI1-FLAG-GPI (blue), and bound human IgG (red) were visualized without cell permeabilization. $\boldsymbol{A}$, Serum from patient \#8 with LE inhibited the interaction of LGI1 with ADAM22 in a dosedependent manner. Scale bar, $20 \mu \mathrm{m}$. Error bars indicate \pm SD. $\boldsymbol{B}$, Most of the sera from patients with monospecific LGI1 trols were freshly obtained and immediately frozen. Sections $(10 \mu \mathrm{m})$ immunoreacted with the patient serum (\#161, diluted 1:500) and antiProx1 were incubated with Cy3- and Alexa Fluor 488-conjugated secondary antibodies. Detailed procedures were described previously (Fukata et al., 2013).

For Figure 7, $\mathrm{LGI}^{-1-}$ (P20) mice and their littermate controls were anesthetized by pentobarbital (75 mg/kg, i.p.) and perfused with $4 \%$ paraformaldehyde in $0.1 \mathrm{M} \mathrm{PB}$. Pairs of mutant and control brains were embedded in single paraffin blocks. Paraffin sections $(4 \mu \mathrm{m}$ in thickness) were successively incubated with 1 $\mathrm{mg} / \mathrm{ml}$ pepsin in $0.2 \mathrm{~N} \mathrm{HCl}$ at $37^{\circ} \mathrm{C}$ for $6 \mathrm{~min}$ (Watanabe et al., 1998), 10\% normal donkey serum for $20 \mathrm{~min}$, primary antibodies diluted in PBS (anti-GluA1, $1 \mu \mathrm{g} / \mathrm{ml}$; vGluT1, $1 \mu \mathrm{g} /$ $\mathrm{ml}$ ) overnight, biotinylated secondary antibodies (1:200, Jackson ImmunoResearch) for $2 \mathrm{~h}$, and streptavidin-peroxidase (Nichirei) for $30 \mathrm{~min}$. Immunoreaction was visualized using the tyramide signal amplification kit with fluorescein tyramide (PerkinElmer Life Sciences). Images were taken using an epifluorescence stereomicroscope equipped with a digital camera (DP70; Olympus).

In situ hybridization. Complementary DNA fragments of mouse vGluT1 (nucleotides 3011680; GenBank accession number BC054462), mouse GAD67 (1036-2015; NM_008077), mouse LGI1 (1-503; NM_020278), mouse ADAM22 (1351-1960; HM004095), and mouse ADAM23 (1991-2490; NM_011780) were subcloned into the pBluescript II and used for the preparation of fluorescein-labeled cRNA probes. Adult C57BL/6 mice were used. Subsequent detailed procedures were described previously ( $\mathrm{Ya}$ masaki et al., 2010).

Statistical analysis. Statistical comparisons between two groups or multiple groups were performed by the Student's $t$ test or one-way

$\leftarrow$

antibodies (absorbance $>0.8$ in ELISA) inhibited the interaction of $\mathrm{LGl} 1$ with ADAM22. A limited number of serum samples with high levels of LGI1 antibodies did not show the inhibition under the condition (light gray). Red text, patients with LE; blue text, patients with NMT. Error bars indicate $\pm \operatorname{SEM}(n=$ 3). ${ }^{*} p<0.05 ;{ }^{* *} p<0.01 ;{ }^{* * *} p<0.001$. C, Serum from an MG patient with monospecific antibodies to DCC (\#144) specifically inhibited the interaction between DCC and its ligand, Netrin-1. Bound ADAM22ex-HA or Netrin-1-FLAG is shown (gray scale) and the merged images of surface-expressed LGI1-FLAG-GPI or DCC (green) and bound human IgG (red) are shown in insets. Scale bar, $20 \mu \mathrm{m}$. D. The inhibitory effect on the DCC-Netrin-1 interaction was shared with DCC antibodies from NMT patients (\#6 and \#21). Error bars indicate \pm SD. Statistical analyses were performed by one-way ANOVA followed by Dunnett's post hoc analysis $(\boldsymbol{A}, \boldsymbol{B}, \boldsymbol{D})$. $\boldsymbol{E}$, The inhibitory effect of LGI1 antibodies on the LGI1-ADAM22 interaction is specifically observed in sera from patients with $L E$, but not with NMT. LGI1 Ab-positive patient sera (absorbance $>0.5$ in ELISA) with LE or NMT were tested as in $\boldsymbol{B}$, and their induced reductions in the LGI1-ADAM22 interaction are shown as the inhibitory effect (\%). Statistical analyses were performed by one-way ANOVA followed by Tukey's post hoc analysis. n.s., not significant 
ANOVA with Tukey's or Dunnett's post hoc analysis, respectively. Fisher's two-sided exact test was used for the data shown in Table 2. Box-and-whisker plots are shown to identify the median, 25th, and 75th percentiles and the extremes.

\section{Results}

Screening patient sera with immunemediated neurological disorders for LGI1 autoantibodies

To select the sera containing LGI1 autoantibodies and to cover as many autoantibodies involved in LE or NMT as possible, we analyzed serum samples from 145 patients who were diagnosed with immune-mediated neurological disorders including LE, NMT, MoS, and Others (Table 1; see Materials and Methods). We screened serum antibodies for binding to the cell surface of cultured rat hippocampal neurons (the identity between human and rat LGI1 proteins is 97\%). The serum from 48 patients bound to the neuronal cell surface and showed various staining patterns (Fig. 1A), suggesting that these target antigens were different. Target proteins were then immunoprecipitated from cultured neurons with the bound serum antibodies and identified using mass spectrometry (Fig. 1B). Specific proteins were immunoprecipitated by individual sera: for example, the serum from patients \#149, \#1, and \#53 immunoprecipitated protein bands of 60,170 , and $100 \mathrm{kDa}$, respectively, and they were identified as LGI1, CASPR2, and GluA subunits of AMPARs, respectively. In addition to these previously reported antigens, we identified several novel candidates including DPP10 (90 kDa), DCC (180 kDa), CSMD1 (>300 kDa), ODZ1/4 (> 300

$\mathrm{kDa})$, and TMEM132A (160 kDa). We noted that some serum antibodies isolated more than one protein. For example, CASPR2, DPP6, and DPP10 were detected in the immunoprecipitate of serum \#27. However, it is not sufficient to conclude that these patients have multiple antibodies against different proteins, because some proteins might be coimmunoprecipitated with the target antigen.

Using the cell-based binding assay with heterologous cells, we next determined the direct cell surface antigens of serum antibodies. The identified candidate proteins were displayed on the surface of COS7 cells and the cells were incubated with the patient's serum. To display a secretory protein LGI1 on the cell surface, a GPI anchor signal was added to the C terminus of LGI1. We confirmed the presence of known autoantibodies against LGI1 (Fig. 2A), GluA2, and CASPR2 (data not shown) and determined several novel autoantibodies against: (1) DCC, a receptor for axon guidance molecule Netrin-1 (Horn et al., 2013); (2) DPP10, an auxiliary subunit of Kv4.2 (Lai and Jan, 2006); (3) ADAM23, one of receptors for LGI1 (Fukata et al., 2006); (4) CSMD1, a neuronal transmembrane protein associated with schizophrenia (Ripke et al., 2011); (5) ODZ1, a neuronal trans-

\section{B}
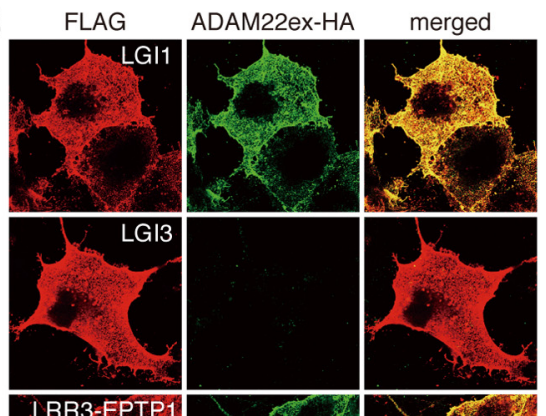

EPTP3 LRR1-EPTP3
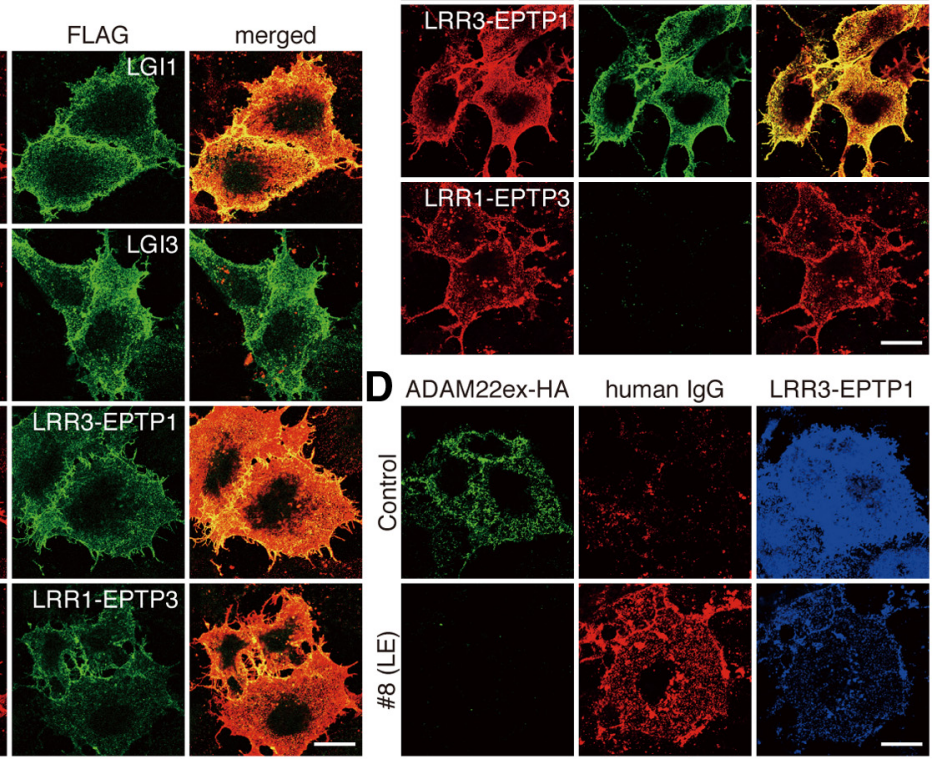

LRR3-EPTP1

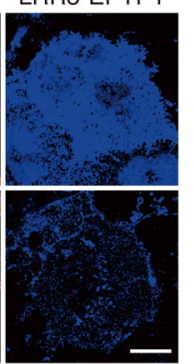
13; EPTP1 or 3, EPTP repeat domain of LGI1 or LI3 B Binding of soluble ADAM22 -HA (green) onto the cell surface of COS7 cells expressing indicated chimeric LGI-FLAG-GPI constructs (red). The EPTP repeat domain of LGI1 (EPTP1) specifically mediated LRR3-EPTP1-FLAG-GPI and subjected to the assay same as that in Figure 4A. Serum antibodies (\#8; red) bound to the LRR3-EPTP1 (blue) and inhibited the binding of LRR3-EPTP1 with ADAM22 (green). Scale bars, $20 \mu \mathrm{m}(\boldsymbol{B}-\boldsymbol{D})$.

membrane protein; and (6) TMEM132A, an uncharacterized transmembrane protein (Oh-hashi et al., 2010) (Fig. 2A). Some patients had antibodies against more than one target antigen (Fig. 2B).

\section{Cell-based ELISA arrays reveal an exclusive role for LGI1 autoantibodies in LE}

To investigate the relative contribution of individual antibodies to diseases, we developed the quantitative cell-based ELISA test against LGI1, CASPR2, DCC, and DPP10, the top four of frequent autoantigens in the present screening (data not shown). The assay was specific and showed a linear correlation for dilution linearity (Figure $3 A$ shows an example of serum \#4, $r=$ 0.936, against LGI1). All serum data from 145 patients were sorted in descending order of the anti-LGI1 (Fig. $3 B$ ) or antiCASPR2 (Fig. 3C) ELISA values to generate heat maps. We observed that $85.3 \%(29 / 34)$ of patients with high levels of LGI1 antibodies (absorbance $>0.8$ ) had been diagnosed with $\operatorname{LE}(p<$ 0.0001 ; Fig. $3 B$, Table 2$)$, and most of these LE patients $(26 / 29$, $89.7 \%$ ) had only the LGI1 autoantibody (without CASPR2, DCC, or DPP10 antibodies). In contrast, $75.0 \%$ (9/12) of patients with CASPR2 antibodies (absorbance $>0.3$ ) had been diagnosed with NMT/MoS ( $p<0.0001$; Fig. $3 C$, Table 2$)$, and all of these patients 

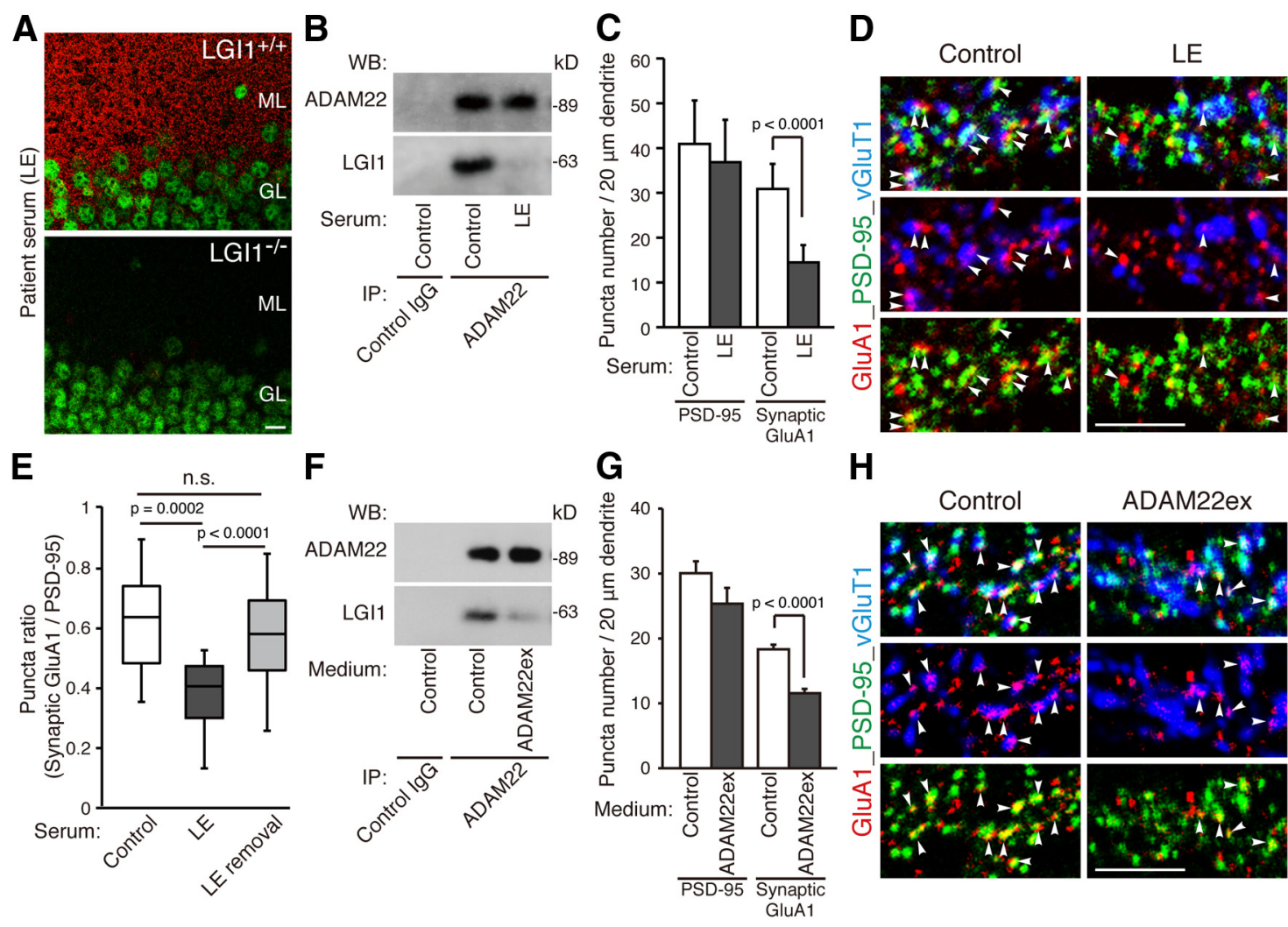

Figure 6. LGI1 antibodies reduce synaptic AMPARs by blocking the LGI1-ADAM22 interaction in neurons. A, Brain sections of the wild-type (LGI1 ${ }^{+/+}$, top) and LGI1 KO (LGI1 ${ }^{-/-}$, bottom) mice were incubated with the serum from a patient with LE (\#161). The patient serum showed a strong punctate labeling (red) in neuropils of dentate gyrus in the wild-type mouse, whereas all the reactivity was abolished in the LGI1 K0 mouse, indicating that the patient serum antibodies were specifically directed against LGI1. Prox1 was visualized (green) to mark granule cell nuclei. ML, molecular layer; GL, granule cell layer. Scale bar, $10 \mu \mathrm{m}$. B. Cultured hippocampal neurons were incubated with patient serum (\#161, LE) or control serum (control \#19) for $3 \mathrm{~d}$. ADAM22 was immunoprecipitated by ADAM22 antibody-conjugated beads. Samples of immunoprecipitates (IP) were analyzed by Western blotting (WB). $\boldsymbol{C}-\boldsymbol{E}$, LGI1 autoantibodies reversibly reduce synaptic AMPARs in hippocampal neurons. Representative images of surface GluA1 clusters (red) in neurons treated with control or the patient (LE, \#161) serum are shown (D). The number of synaptic GluA1 clusters (arrowheads), which were apposed to both vGluT1 (blue) and PSD-95 (green), was significantly reduced by the treatment with patient serum. $n=3$ experiments (C). The reduction of synaptic GluA1 was reversed after the patient serum was removed. $n=24$ dendrites from two independent experiments. Statistical analyses were performed by one-way ANOVA followed by Tukey's post hoc analysis $(\boldsymbol{E}) . \boldsymbol{F}$, Cultured hippocampal neurons were incubated with medium containing the soluble form of ADAM22 (ADAM22ex) or control medium for $3 \mathrm{~d}$. Endogenous ADAM22 was then immunoprecipitated as described in $\boldsymbol{B} . \mathbf{G}, \boldsymbol{H}$, The number of synaptic GluA1 was significantly reduced by the treatment with ADAM22ex. Representative images of surface GluA1 clusters (red) in neurons treated with control medium or ADAM22ex-containing medium are shown $(\boldsymbol{H})$. The number of synaptic GluA1 clusters (arrowheads), which were apposed to both vGluT1 (blue) and PSD-95 (green), was significantly reduced by treatment with ADAM22ex. $n=3$ experiments (G). Error bars indicate \pm SEM. Scale bars, $5 \mu \mathrm{m}$.

concurrently had multiple antibodies to LGI1, DCC, and/or DPP10 (also see Fig. 2B). To further examine the relationship between LGI1 and CASPR2 antibodies in patients with LE or NMT, we generated a scatterplot (Fig. 3D). Distinct tendencies were noted: high levels of anti-LGI1 $(>0.8)$ were associated with LE independently of anti-CASPR2 and anti-CASPR2 reactivity $(>0.3)$ was associated with NMT and was concurrently accompanied by moderate levels of anti-LGI1 reactivity $(0.5-1.0)$. Importantly, retrospective investigations revealed that two of the three LE cases with CASPR2 antibodies $(>0.3$; patients \# 9 and \#27, Fig. 3C,D, asterisks) had experienced peripheral nerve symptoms as NMT, supporting that CASPR2 antibodies are specifically associated with the NMT feature $(p<0.0001$; Table 2$)$. These results indicate that, among the identified autoantibodies, LGI1 autoantibodies play an exclusive role in LE and strongly suggest that our established ELISA arrays can be immediately applicable to clinical practice.

Conversely, DCC antibodies occurred in seven patients with NMT/MoS and in four patients with LE, and in all of these cases, DCC antibodies co-occurred with CASPR2 and/or LGI1 antibodies (Fig. $3 B, C$ ). DCC antibodies appeared to be significantly associated with NMT/MoS $(p<0.01$; Table 2$)$. Uniquely, DCC antibodies were solely detected in one isolated MG patient (\#144; Table 2). DCC antibodies were also detected in the Other category of diseases, such as multiple system atrophy and amyotrophic lateral sclerosis, but were not detected in 23 healthy controls (data not shown).

\section{LGI1 autoantibodies block the binding of LGI1 to ADAM22}

We next explored a mode of action of LGI1 antibodies. Of the three proposed functions of LGI1 (see Introduction), we first investigated whether the LGI1 autoantibody directly affects the interaction of LGI1 with its major receptor, ADAM22, because there has been no evidence concerning a direct interaction between the Kv1 channel and LGI1. In addition, it seems unlikely that the autoantibody subacutely affects the development and remodeling of the neural circuits in the adult brain. When COS7 cells transfected with LGI1 tagged with FLAG-GPI were incubated with the soluble extracellular domain of ADAM22 (ADAM22exHA), ADAM22ex-HA specifically bound to LGI1-FLAG-GPI on the cell surface (Fig. $4 A$ ). In contrast, when cells were pretreated with the serum from a patient with $\mathrm{LE}(\# 8)$, which contains monospecific antibodies to LGI1 (absorbance 1.33 in ELISA), the interaction of LGI1 with ADAM22 was significantly inhibited in a dose- 


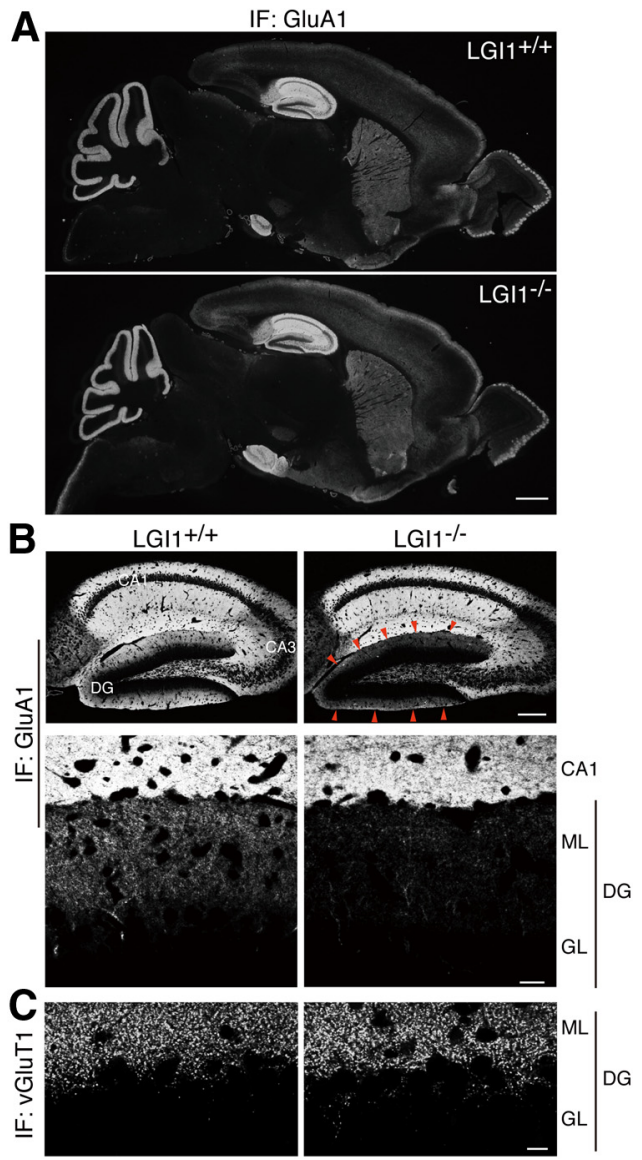

Figure 7. Genetic deletion of $L G \mid 1$ results in specific reduction of AMPARs in the hippocampal dentate gyrus. $A$, Immunofluorescence (IF) for GluA1 subunit of AMPARs in parasagittal sections of control wild-type $\left(\mathrm{LGI}^{+/+}\right)$and $\mathrm{LGl1} \mathrm{KO}\left(\mathrm{LGl} 1^{-/-}\right)$mice. $\boldsymbol{B}$, Immunofluorescence for GluA1 in the hippocampus. The region including dentate gyrus (molecular and granule cell layers) and CA1 (molecular layer) was magnified (bottom). Note a marked decrease for GluA1 in the dentate molecular layer of $\mathrm{LGI}^{-1-}$ mice (red arrowheads). Images from control and $\mathrm{LGI}^{-1-}$ mice were captured at the same gain levels. Representative data from three independent experiments are shown. $C$, No changes were observed for vGluT1 immunoreactivity in the dentate molecular layer of $\mathrm{LGI}^{-1-}$ mice. Scale bars: $\boldsymbol{A}, 1 \mathrm{~mm} ; \boldsymbol{B}, 200 \mu \mathrm{m} ; \boldsymbol{B}$, bottom, $20 \mu \mathrm{m}$; and $C, 10 \mu \mathrm{m}$. DG, dentate gyrus; ML, molecular layer; GL, granule cell layer.

dependent manner (Fig. 4A). The serum also inhibited the interaction of LGI1 with another receptor, ADAM23 (Fig. 4A). In addition, most of sera from patients with LE containing monospecific LGI1 antibodies (absorbance $>0.8$ in ELISA) significantly inhibited the LGI1-ADAM22 interaction (Fig. 4B). Under experimental conditions, control sera and the patient serum containing CASPR2 antibodies without LGI1 antibodies (\#17) did not affect the binding of LGI1 to ADAM22 (one representative control is shown from four independent control samples tested). The inhibitory effect of LGI1 antibodies was specific to the LGI1-ADAM22 interaction because the patient serum (\#149) did not affect the ligand-receptor interaction of Netrin-1 with DCC (Fig. 4C). In contrast, serum from \#144, which contained monospecific antibodies to DCC (1.59 in ELISA; a patient with $\mathrm{MG}$ ), specifically inhibited the interaction of Netrin-1 with DCC (Fig. 4C). Furthermore, some of other DCC antibodies detected in patients with NMT (patients \#6 and \#21) inhibited the Netrin-1-DCC interaction (Fig. 4D).

We also examined the disease specificity of the effect of LGI1 antibodies on the LGI1-ADAM22 interaction. As shown in Figure $4 B$, the inhibitory effect of sera with monospecific LGI1 antibodies (absorbance $>0.8$ in ELISA) was shared among patients with LE, but, importantly, not in NMT patients (patients \#5 and \#52). We reassessed the inhibitory effect of all the anti-LGI1 sera from patients with LE and NMT (absorbance $>0.5$ in ELISA; Fig. $4 E)$. Importantly, anti-LGI1 sera from patients with LE significantly inhibited the LGI1-ADAM22 binding ( $p<0.0001)$, whereas anti-LGI1 sera from patients with NMT did not (not significantly different from control serum group without LGI1 antibodies). Together, these results strongly suggest that the antibody-mediated inhibition of the LGI1-ADAM22 interaction is a pathogenic mechanism for LE.

We next mapped the epitope of LGI1 autoantibodies to further determine the specificity of the inhibitory effect of the serum. LGI1 has leucine-rich repeat (LRR) and EPTP repeat domains, and the EPTP repeat domain mediates ADAM22 binding (Fukata et al., 2006). LGI3, a member of LGI1 family proteins, also contains LRR and EPTP repeat domains, but does not bind to ADAM22 (Fukata et al., 2010). We generated two chimeric constructs between LGI1 and LGI3: LRR3-EPTP1, consisting of the LRR domain of LGI3 and EPTP of LGI1, and LRR1-EPTP3, derived from the LRR domain of LGI1 and EPTP of LGI3 (Fig. 5A). As expected, the cell surface binding assay showed that LGI1 and LRR3EPTP1, but neither LGI3 nor LRR1-EPTP3, bound to ADAM22 (Fig. 5B). We next investigated whether serum LGI1 antibodies bind to the EPTP repeat and prevent LGI1 from interacting with ADAM22. When transfected COS7 cells were incubated with the serum from an LE patient containing LGI1 antibodies, the antibodies bound to LGI1, LRR3-EPTP1, and LRR1-EPTP3, but not to LGI3 (Fig. $5 C$ ), indicating that serum contains polyclonal LGI1 antibodies and that their epitopes are distributed to both LRR and EPTP repeat domains of LGI1. Indeed, all of the tested sera from patients with LGI1 antibodies showed binding to both LRR and EPTP repeat domains of LGI1 (data not shown). We found that the serum antibodies inhibited the binding of LRR3-EPTP1 to ADAM22 (Fig. 5D), indicating that LGI1 antibodies neutralize the receptor binding activity of LGI1 by acting on the EPTP repeat domain of LGI1.

\section{Loss of LGI1-ADAM22 interaction reversibly reduces synaptic AMPARs}

We next investigated whether LGI1 antibodies inhibit the interaction of endogenous LGI1 with ADAM22 in hippocampal neurons. We used serum \#161, because this serum was monospecific against LGI1 (tested in Fig. 3: LGI1 ELISA value, 1.86; CASPR2, 0.16; DCC, 0.10 ; DPP10, - 0.17) and showed the strongest inhibitory effect in COS7 cells (Fig. 4B). Consistently, comparative immunohistochemistry with brain sections of the wild-type and LGI1 KO mice showed the selective lack of reactivity of the serum \#161 in the brain of the LGI1 KO mice (Fig. 6A). When ADAM22 was immunoprecipitated from cultured hippocampal neurons treated with control serum, LGI1 was efficiently coimmunoprecipitated (Fig. 6B). In contrast, when neurons were pretreated with the patient serum, the amount of coimmunoprecipitated LGI1 was significantly reduced $(23.7 \pm 1.92 \%$ of control; $p=0.027 ; n=3)$.

In LGI1 KO mice, AMPAR-mediated synaptic transmission is reduced in the hippocampus and lethal epilepsy inevitably occurs (Fukata et al., 2010). However, it remains unclear whether acute disruption of the LGI1-ADAM22 interaction affects synaptic AMPARs. When hippocampal neurons were treated with the patient serum for $3 \mathrm{~d}$, the number of synaptic GluA1 clusters was significantly reduced $(p<0.0001)$, whereas that of PSD-95, a postsynaptic scaffolding protein, did not change (Fig. $6 C, D$ ). Importantly, the effect on synaptic AMPARs was reversed by removal of serum antibodies from the neuronal cultures (Fig. 6E), providing a possible explanation for the improvement of LE 

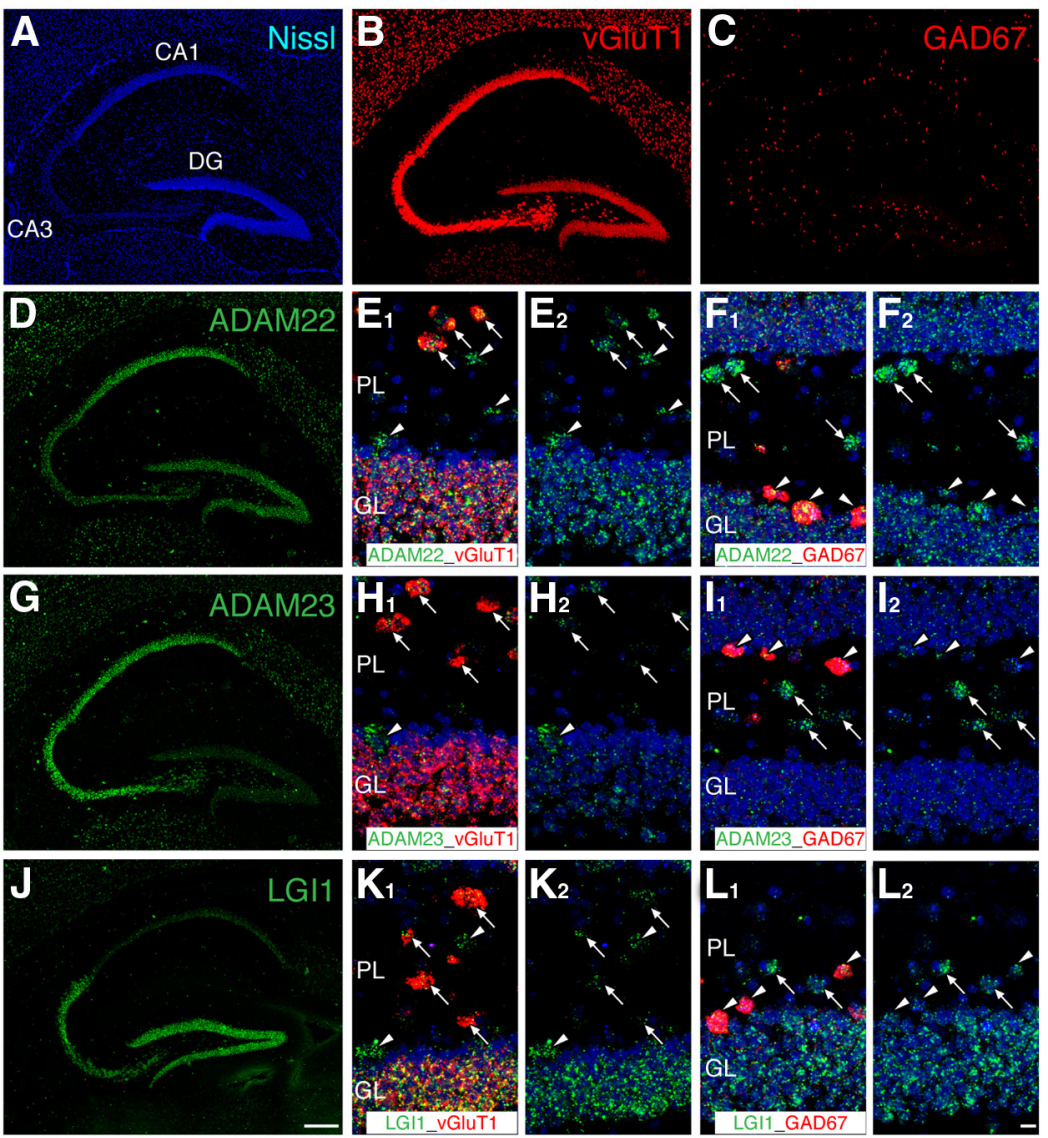

M

IF: ADAM22_human IgG_GAD67

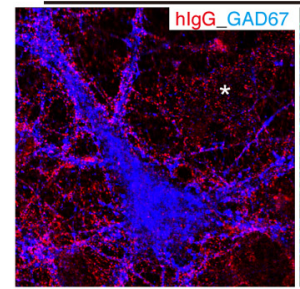

$\mathbf{N}$
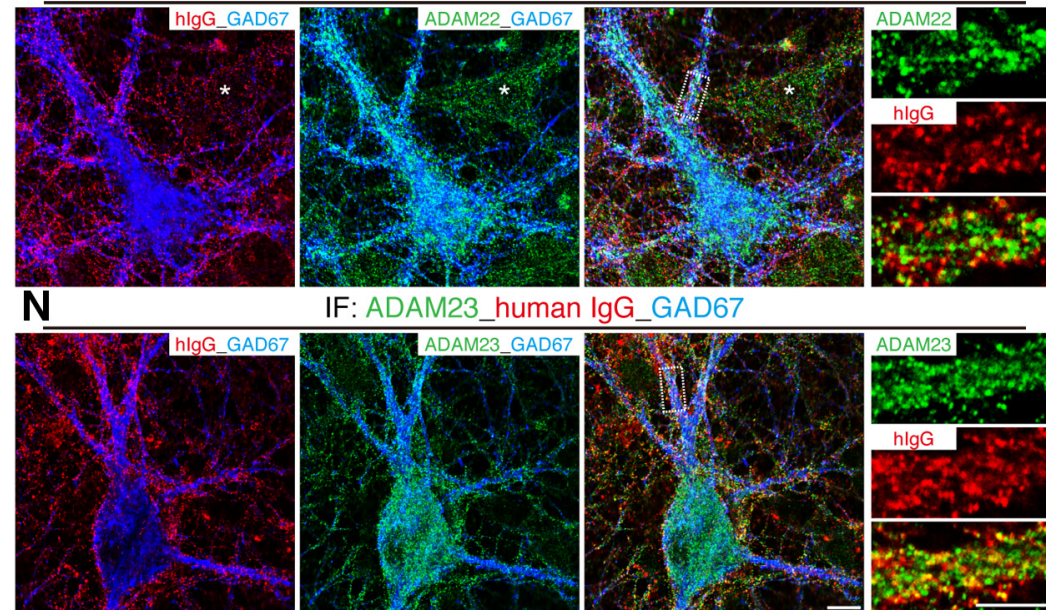

IF: ADAM23_human IgG_GAD67
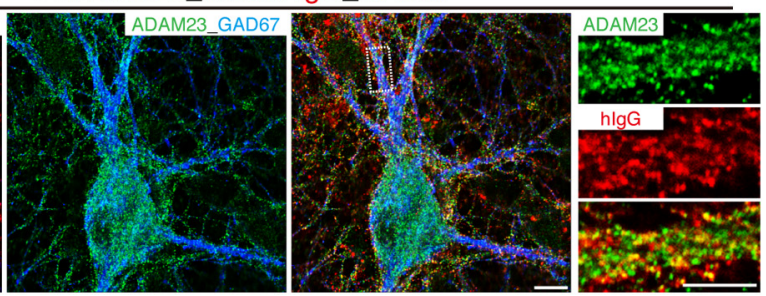

Figure 8. ADAM22, ADAM23, and LGI1 are expressed in inhibitory interneurons and in excitatory neurons in the hippocampus. $\boldsymbol{A}-\boldsymbol{L}$, Double-fluorescent in situ hybridization for ADAM22, ADAM23, or LGI1 and vGluT1 or GAD67 in the mouse hippocampus. Neurons were identified with Nissl staining $(\boldsymbol{A}, \boldsymbol{E}, \boldsymbol{F}, \boldsymbol{H}, \boldsymbol{I}, \boldsymbol{K}, \boldsymbol{L} ;$ blue). vGluT1 (B) and GAD67 (C) mRNAs (red) were used as markers of glutamatergic and GABAergic neurons, respectively. ADAM22 (D), ADAM23 (G), and LGI1 (J) mRNAs are shown in green. The polymorphic cell layer $(\mathrm{PL})$ of the dentate hilus is magnified $(\boldsymbol{E}, \boldsymbol{F}, \operatorname{ADAM} 22 ; \boldsymbol{H}, \boldsymbol{I}, \mathrm{ADAM} 23$; $\boldsymbol{K}, \boldsymbol{L}, \mathrm{LGI} 1)$. Signals for ADAM22, ADAM23, and LGI1 mRNAs overlapped with those for vGluT1 $\left(\boldsymbol{E}_{\mathbf{1}}, \boldsymbol{H}_{\mathbf{1}}, \boldsymbol{K}_{\mathbf{1}}\right.$, arrows) and GAD67 mRNAs ( $\boldsymbol{F}_{1}, \boldsymbol{I}_{1}, \boldsymbol{L}_{1}$, arrowheads). Arrowheads in $\boldsymbol{E}, \boldsymbol{H}$, and $\boldsymbol{K}$ indicate vGluT1-negative hilar neurons and arrows in $\boldsymbol{F}, \boldsymbol{I}$, and L indicate GAD67-negative hilar neurons. Scale bars, $200 \mu \mathrm{m}$ (10 $\mu \mathrm{m}$, magnified). DG, dentate gyrus; GL, granule cell layer. $M, N$, LG11 associates with ADAM22 and ADAM23 on hippocampal inhibitory interneurons. Rat cultured hippocampal neurons (19 DIV) were triply stained by anti-GAD67 (blue, pseudocolor), anti-ADAM22 (M), or ADAM23 ( $\boldsymbol{N}$; green), and the patient serum (\#161) human lgG (hlgG) that was monospecific to LGI1 (red, pseudocolor). Cell surface LGI1 signals were colocalized with ADAM22 and ADAM23 signals on GAD67-positive inhibitory interneurons (right, magnified view of the region indicated by dashed square). An asterisk $(\boldsymbol{M})$ indicates the GAD67-negative excitatory neuron, in which ADAM22 was expressed and to which LGI1 bound. Scale bars, $10 \mu \mathrm{m}$ (5 $\mu \mathrm{m}$, magnified). symptoms after plasma exchange (Vincent et al., 2006; Lancaster and Dalmau, 2012). Furthermore, application of soluble ADAM22 fragment (ADAM22ex) to the neuron culture inhibited the interaction of LGI1 with endogenous ADAM22 $(30.0 \pm 7.3 \%$ of control; $p=0.0036 ; n=$ 3 ; Fig. $6 F$ ) and reduced synaptic AMPARs $(p<0.0001$; Fig. $6 G, H)$, indicating that the impaired interaction of LGI1 with ADAM22 is sufficient to cause the reduction of synaptic AMPARs. Therefore, the effect of the patient serum on AMPARs is specifically attributed to the LGI1 antibody-mediated inhibition of LGI1-ADAM22 interaction.

Next, we examined whether genetic deletion of LGI1, which causes lethal epilepsy in mice, affects AMPAR expression in the brain. We performed immunofluorescence examination of the LGI1 KO mouse brain using GluAl subunitspecific antibody (Yamazaki et al., 2010). To reliably evaluate genotypic differences, a pair of littermate control $\left(\mathrm{LGI}^{+/+}\right)$and $\mathrm{KO}\left(\mathrm{LGI}^{-1-}\right)$ mouse brains at P20 were embedded in single paraffin blocks, mounted on the same glass slides, and subjected to immunohistochemical incubation under the same conditions. Overall GluA1 distribution was as described previously (Yamasaki et al., 2011; Fig. 7A). In the hippocampal formation of control mouse brain, the neuropil of dentate gyrus, CA1, and CA3 was strongly immunostained. In the LGI1 KO mice, GluA1 immunoreactivity was robustly reduced in the dentate gyrus, particularly in the molecular layer (Fig. 7B), where the immunoreactivity of ADAM22 and ADAM23 is greatly reduced (Fukata et al., 2010). Under these conditions, no such changes were observed for vGluT1, a marker protein for glutamatergic axon terminals (Fig. 7C).

\section{ADAM22 and ADAM23 are expressed} in inhibitory and excitatory neurons in the hippocampus

Why does the AMPAR-function reduced by the LGI1 antibodies or genetic loss of LGI1 cause seizures that result from neuronal hyperexcitation? In the hippocampus, many inhibitory interneurons constitute strong feedback or feedforward inhibition loops (Acsády et al., 1998), and the reduced activity of inhibitory interneurons may cause overall network hyperexcitability. To explore a possibility that LGI1 acts on the inhibitory neurons to regulate their AMPAR function, we first examined the cellular expression of ADAM22, ADAM23, and LGI1 mRNAs by double fluorescent in situ hybridization with vGluT1 or GAD67, 
markers of glutamatergic excitatory neurons or GABAergic inhibitory interneurons, respectively (Fig. $8 A-L$ ). Overall, ADAM22, ADAM23, and LGI1 mRNAs were coexpressed with vGluT1 mRNA in principal excitatory neurons in CA1, CA3, and dentate gyrus of the hippocampus, except that ADAM23 mRNA was little expressed in dentate granule cells (Fig. $8 B, D, G, J$ ). At a high magnification of the dentate hilus (Fig. 8E,F; H,I; K,L), mRNAs of ADAM22, ADAM23, and LGI1 were coexpressed in the neurons expressing GAD67 mRNA (indicated by arrowheads), in addition to the neurons expressing vGluT1 mRNA (representing excitatory hilar mossy cells, indicated by arrows). These results indicate that inhibitory interneurons and excitatory neurons in the hippocampus express ADAM22, ADAM23, and LGI1.

We next investigated whether LGI1 associates with ADAM22/23 on inhibitory interneurons by immunofluorescence analysis (Fig. $8 M, N$ ). Rat cultured hippocampal neurons were stained triply by anti-GAD67, anti-ADAM22 or anti-ADAM23, and the patient serum (\#161) that was monospecific to LGI1 (Figs. 3, 6A) and was used for the staining of surface-bound LGI1. Consistent with mRNA expression patterns, ADAM22 and ADAM23 proteins were expressed in GAD67-expressing interneurons. We found that cell surface LGI1 signals were present as small clusters on all neurons in the culture, consistent with a previous report (Lai et al., 2010). The LGI1 signals were detected at the surface of both GAD67-negative and GAD67-positive neurons and colocalized with ADAM22 and ADAM23 signals at the dendrite and soma of the GAD67-positive inhibitory interneurons. These results support a hypothesis that the reduced AMPAR function in inhibitory interneurons by the reduced LGIl function could cause disinhibition of neural networks leading to the seizure. Consistently, the autoantibodies to AMPARs produced in LE patients with seizures reduce synaptic AMPARs in cultured hippocampal neurons (Lai et al., 2009).

\section{Discussion}

Understanding a pathogenic mechanism for LGI1-mediated epilepsy represents an important goal of this study. For this purpose, we paid attention to the mode of action of LGI1 autoantibodies in LE. Previous studies showed that autoantibodies against NMDAR and AMPAR induce the internalization of the corresponding receptors and reduce the synaptic receptors (Lai et al., 2009; Hughes et al., 2010). Similar to MG and Lambert-Eaton syndrome, the functional downregulation of target ion channels has been a common mechanism of autoimmune encephalitis (i.e., autoimmune channelopathies). In contrast, the mode of action of LGI1 antibodies shown here is unique in that antibodies neutralize the specific protein-protein interaction (between LGI1 and ADAM22/ADAM23). Because the genetic deletion of LGI1, ADAM22, or ADAM23 causes lethal epilepsy in mouse models (Mitchell et al., 2001; Sagane et al., 2005; Owuor et al., 2009; Chabrol et al., 2010; Fukata et al., 2010; Yu et al., 2010) and because secretion-deficient LGI1 mutations occur in ADLTE (Senechal et al., 2005; Nobile et al., 2009), the reduced LGI1ADAM22/23 interaction is the most reasonable pathogenic mechanism for LE characterized by seizures and amnesia.

This study strongly suggests that certain forms of inherited epilepsy and acquired seizures share the common mechanism that inhibition of the LGI1-ADAM22 interaction reduces synaptic AMPARs. How does LGI1 regulate synaptic AMPARs? AMPARs are anchored at the synapse through the interaction of their auxiliary subunit transmembrane AMPA receptor regulatory proteins (TARPs) with PSD-95 (Nicoll et al., 2006). This interaction is mediated through the PDZ1 or PDZ2 domain of PSD-95 (Elias and Nicoll, 2007), whereas ADAM22 binds to the
PDZ3 domain-containing region of PSD-95 (Fukata et al., 2006). Given that AMPARs and ADAM22 are anchored by the common PSD-95-scaffolding platform through different PDZ domains, it is speculated that the AMPAR/TARP can more stably bind to PSD-95 when LGI1/ADAM22 coincides. Because Kv1.1 and Kv1.2 VGKC proteins also bind to the PDZ1 or PDZ2 domain of PSD-95 (Kim et al., 1995) and are indirectly associated with LGI1 through ADAM22 (Fukata et al., 2010), LGI1-ADAM22 interaction may similarly promote the Kv1 binding to PSD-95. Further structural and biochemical studies are required to address that LGI1-ADAM22 interaction regulates the scaffolding activity of PSD-95.

LGI1 has two domains, the LRR and EPTP repeat domains, and the EPTP repeat domain mediates ADAM22/23 binding ( $\mathrm{Fu}-$ kata et al., 2006). Our epitope mapping showed that all the patient LGI1 autoantibodies tested were polyclonal antibodies recognizing both the LRR and EPTP repeat domains (Fig. $5 C$ ). In this study, we showed that LGI1 antibodies inhibit the interaction of LGI1 with ADAM22 by binding to the EPTP domain (Fig. $5 D$ ). Given that the LRR domain is frequently involved in the formation of protein-protein interaction (de Wit et al., 2011), it is suggested that LGI1 autoantibodies are involved in the pathogenesis of LE by binding to the LRR domain of LGI1 in addition to the EPTP domain. One possible candidate that may interact with the LRR domain of LGI1 is a Nogo receptor $1(\mathrm{NgR} 1)$, an LRR domain-containing GPI-anchored protein. It has been reported recently that $\mathrm{NgR} 1$ functions as a receptor of LGI1 and facilitates LGI1 binding to ADAM22 (Thomas et al., 2010). Because the LRR domain can mediate the heteromeric LRR-LRR interaction (Bella et al., 2008), it may be worthwhile to investigate whether NgR1 binds to the LRR domain of LGI1 and, if so, whether LGI1 antibodies inhibit the binding of NgR1 to LGI1. Further studies are required to address this possibility.

In the course of screening for LGI1 antibodies, we additionally identified novel autoantibodies, including DCC, DPP10, ADAM23, CSMD1, ODZ1, and TMEM132A. Netrin-1 and DCC mediate axon guidance during development. A recent study reported that the loss of DCC in the adult mouse brain results in impaired memory (Horn et al., 2013). Together with our finding that newly identified DCC antibodies block the ligand/receptor interaction between Netrin-1 and DCC (Fig. 4C,D), DCC antibodies may modify clinical symptoms of LE. We also identified DPP10, an auxiliary subunit of Kv4.2, as a novel autoantigen in patients with NMT, LE, MoS, and encephalitis. Although we found that DPP10 always coexisted with DPP6 at similar levels in the immunoprecipitates from neurons (Fig. 1B), antibodies that bind directly to DPP6 or Kv4.2 were not detected in the sera (data not shown), suggesting that DPP6 is physically associated with DPP10 in neurons. Given that DPP6, but not DPP10, was reported as a novel autoantigen of a protracted encephalitis with diarrhea (Boronat et al., 2013), DPP10 antibodies may be associated with similar clinical symptoms. Due to the limited number of patients in this study, we were unable to correlate the occurrence of DCC or DPP10 antibodies with specific diseases at this stage. However, it is noteworthy that DCC and DPP10 antibodies were significantly associated with specific features such as thymoma, myasthenia gravis, and neuromyotonia (Table 2). Our study should serve as a prototype for future trials to clarify pathogenic roles of DCC and DPP10 antibodies in neuroimmunological disorders. Further assessment of individual serum antibodies and associated clinical symptoms will reveal whether and how these novel autoantibodies are involved in the pathogenesis and phenotypic heterogeneity of LE and NMT. 
This study establishes that LGI1 autoantibodies specifically cause LE through inhibiting the ligand-receptor interaction between LGI1 and ADAM22 that controls AMPAR function. "Blocking the ligand-receptor interaction" is a novel mode of autoantibody-mediated pathogenesis for encephalitis/LE, different from a previous concept, "autoimmune channelopathy." This is akin to inherited epilepsy with LGI1 mutations, the pathogenesis of which cannot be explained by a common "channelopathy" concept. Therefore, this study should provide insights into the molecular basis of genetic and acquired epileptic disorders with LGI1 dysfunction and contribute to understanding the mechanisms for regulating brain excitability and memory storage in human.

\section{References}

Acsády L, Kamondi A, Sík A, Freund T, Buzsáki G (1998) GABAergic cells are the major postsynaptic targets of mossy fibers in the rat hippocampus. J Neurosci 18:3386-3403. Medline

Bella J, Hindle KL, McEwan PA, Lovell SC (2008) The leucine-rich repeat structure. Cell Mol Life Sci 65:2307-2333. CrossRef Medline

Boronat A, Gelfand JM, Gresa-Arribas N, Jeong HY, Walsh M, Roberts K, Martinez-Hernandez E, Rosenfeld MR, Balice-Gordon R, Graus F, Rudy B, Dalmau J (2013) Encephalitis and antibodies to dipeptidylpeptidase-like protein-6, a subunit of Kv4.2 potassium channels. Ann Neurol 73:120-128. CrossRef Medline

Chabrol E, Navarro V, Provenzano G, Cohen I, Dinocourt C, RivaudPéchoux S, Fricker D, Baulac M, Miles R, Leguern E, Baulac S (2010) Electroclinical characterization of epileptic seizures in leucine-rich, glioma-inactivated 1-deficient mice. Brain 133:2749-2762. CrossRef Medline

Dalmau J, Gleichman AJ, Hughes EG, Rossi JE, Peng X, Lai M, Dessain SK, Rosenfeld MR, Balice-Gordon R, Lynch DR (2008) Anti-NMDAreceptor encephalitis: case series and analysis of the effects of antibodies. Lancet Neurol 7:1091-1098. CrossRef Medline

de Wit J, Hong W, Luo L, Ghosh A (2011) Role of leucine-rich repeat proteins in the development and function of neural circuits. Annu Rev Cell Dev Biol 27:697-729. CrossRef Medline

Elias GM, Nicoll RA (2007) Synaptic trafficking of glutamate receptors by MAGUK scaffolding proteins. Trends Cell Biol 17:343-352. CrossRef Medline

Fukata Y, Adesnik H, Iwanaga T, Bredt DS, Nicoll RA, Fukata M (2006) Epilepsy-related ligand/receptor complex LGI1 and ADAM22 regulate synaptic transmission. Science 313:1792-1795. CrossRef Medline

Fukata Y, Lovero KL, Iwanaga T, Watanabe A, Yokoi N, Tabuchi K, Shigemoto R, Nicoll RA, Fukata M (2010) Disruption of LGI1-linked synaptic complex causes abnormal synaptic transmission and epilepsy. Proc Natl Acad Sci U S A 107:3799-3804. CrossRef Medline

Fukata Y, Dimitrov A, Boncompain G, Vielemeyer O, Perez F, Fukata M (2013) Local palmitoylation cycles define activity-regulated postsynaptic subdomains. J Cell Biol 202:145-161. CrossRef Medline

Gu W, Brodtkorb E, Steinlein OK (2002) LGI1 is mutated in familial temporal lobe epilepsy characterized by aphasic seizures. Ann Neurol 52:364367. CrossRef Medline

Horn KE, Glasgow SD, Gobert D, Bull SJ, Luk T, Girgis J, Tremblay ME, McEachern D, Bouchard JF, Haber M, Hamel E, Krimpenfort P, Murai KK, Berns A, Doucet G, Chapman CA, Ruthazer ES, Kennedy TE (2013) DCC expression by neurons regulates synaptic plasticity in the adult brain. Cell Rep 3:173-185. CrossRef Medline

Hughes EG, Peng X, Gleichman AJ, Lai M, Zhou L, Tsou R, Parsons TD, Lynch DR, Dalmau J, Balice-Gordon RJ (2010) Cellular and synaptic mechanisms of anti-NMDA receptor encephalitis. J Neurosci 30:58665875. CrossRef Medline

Irani SR, Alexander S, Waters P, Kleopa KA, Pettingill P, Zuliani L, Peles E, Buckley C, Lang B, Vincent A (2010) Antibodies to Kvl potassium channel-complex proteins leucine-rich, glioma inactivated 1 protein and contactin-associated protein-2 in limbic encephalitis, Morvan's syndrome and acquired neuromyotonia. Brain 133:2734-2748. CrossRef Medline

Irani SR, Pettingill P, Kleopa KA, Schiza N, Waters P, Mazia C, Zuliani L, Watanabe O, Lang B, Buckley C, Vincent A (2012) Morvan syndrome:
Clinical and serological observations in 29 cases. Ann Neurol 72:241-255. CrossRef Medline

Kalachikov S, Evgrafov O, Ross B, Winawer M, Barker-Cummings C, Martinelli Boneschi F, Choi C, Morozov P, Das K, Teplitskaya E, Yu A, Cayanis E, Penchaszadeh G, Kottmann AH, Pedley TA, Hauser WA, Ottman R, Gilliam TC (2002) Mutations in LGIl cause autosomal-dominant partial epilepsy with auditory features. Nat Genet 30:335-341. CrossRef Medline

Kegel L, Aunin E, Meijer DN, Bermingham JR Jr (2013) LGI proteins in the nervous system. ASN Neuro 5:167-181. CrossRef Medline

Kim E, Niethammer M, Rothschild A, Jan YN, Sheng M (1995) Clustering of Shaker-type $\mathrm{K}^{+}$channels by interaction with a family of membraneassociated guanylate kinases. Nature 378:85-88. CrossRef Medline

Kleopa KA, Elman LB, Lang B, Vincent A, Scherer SS (2006) Neuromyotonia and limbic encephalitis sera target mature Shaker-type $\mathrm{K}^{+}$channels: subunit specificity correlates with clinical manifestations. Brain 129: 1570-1584. CrossRef Medline

Lai HC, Jan LY (2006) The distribution and targeting of neuronal voltagegated ion channels. Nat Rev Neurosci 7:548-562. CrossRef Medline

Lai M, Hughes EG, Peng X, Zhou L, Gleichman AJ, Shu H, Matà S, Kremens D, Vitaliani R, Geschwind MD, Bataller L, Kalb RG, Davis R, Graus F, Lynch DR, Balice-Gordon R, Dalmau J (2009) AMPA receptor antibodies in limbic encephalitis alter synaptic receptor location. Ann Neurol 65:424-434. CrossRef Medline

Lai M, Huijbers MG, Lancaster E, Graus F, Bataller L, Balice-Gordon R, Cowell JK, Dalmau J (2010) Investigation of LGI1 as the antigen in limbic encephalitis previously attributed to potassium channels: a case series. Lancet Neurol 9:776-785. CrossRef Medline

Lancaster E, Dalmau J (2012) Neuronal autoantigens-pathogenesis, associated disorders and antibody testing. Nat Rev Neurol 8:380-390. CrossRef Medline

Mitchell KJ, Pinson KI, Kelly OG, Brennan J, Zupicich J, Scherz P, Leighton PA, Goodrich LV, Lu X, Avery BJ, Tate P, Dill K, Pangilinan E, Wakenight P, Tessier-Lavigne M, Skarnes WC (2001) Functional analysis of secreted and transmembrane proteins critical to mouse development. Nat Genet 28:241-249. CrossRef Medline

Miyazaki T, Fukaya M, Shimizu H, Watanabe M (2003) Subtype switching of vesicular glutamate transporters at parallel fibre-Purkinje cell synapses in developing mouse cerebellum. Eur J Neurosci 17:2563-2572. CrossRef Medline

Morante-Redolat JM, Gorostidi-Pagola A, Piquer-Sirerol S, Sáenz A, Poza JJ, Galán J, Gesk S, Sarafidou T, Mautner VF, Binelli S, Staub E, Hinzmann B, French L, Prud'homme JF, Passarelli D, Scannapieco P, Tassinari CA, Avanzini G, Martí-Massó JF, Kluwe L, et al. (2002) Mutations in the LGI1/Epitempin gene on 10q24 cause autosomal dominant lateral temporal epilepsy. Hum Mol Genet 11:1119-1128. CrossRef Medline

Nicoll RA, Tomita S, Bredt DS (2006) Auxiliary subunits assist AMPA-type glutamate receptors. Science 311:1253-1256. CrossRef Medline

Nobile C, Michelucci R, Andreazza S, Pasini E, Tosatto SC, Striano P (2009) LGI1 mutations in autosomal dominant and sporadic lateral temporal epilepsy. Hum Mutat 30:530-536. CrossRef Medline

Noebels JL (2003) The biology of epilepsy genes. Annu Rev Neurosci 26: 599-625. CrossRef Medline

Oh-hashi K, Imai K, Koga H, Hirata Y, Kiuchi K (2010) Knockdown of transmembrane protein $132 \mathrm{~A}$ by RNA interference facilitates serum starvation-induced cell death in Neuro2a cells. Mol Cell Biochem 342: 117-123. CrossRef Medline

Owuor K, Harel NY, Englot DJ, Hisama F, Blumenfeld H, Strittmatter SM (2009) LGI1-associated epilepsy through altered ADAM23-dependent neuronal morphology. Mol Cell Neurosci 42:448-457. CrossRef Medline

Poliak S, Gollan L, Martinez R, Custer A, Einheber S, Salzer JL, Trimmer JS, Shrager P, Peles E (1999) Caspr2, a new member of the neurexin superfamily, is localized at the juxtaparanodes of myelinated axons and associates with $\mathrm{K}^{+}$channels. Neuron 24:1037-1047. CrossRef Medline

Ripke S, Sanders AR, Kendler KS, Levinson DF, Sklar P, Holmans PA, Lin DY, Duan J, Ophoff RA, Andreassen OA, Scolnick E, Cichon S, St Clair D, Corvin A, Gurling H, Werge T, Rujescu D, Blackwood DH, Pato CN, Malhotra AK, et al. (2011) Genome-wide association study identifies five new schizophrenia loci. Nat Genet 43:969-976. CrossRef Medline

Sagane K, Hayakawa K, Kai J, Hirohashi T, Takahashi E, Miyamoto N, Ino M, Oki T, Yamazaki K, Nagasu T (2005) Ataxia and peripheral nerve hypo- 
myelination in ADAM22-deficient mice. BMC Neurosci 6:33. CrossRef Medline

Schulte U, Thumfart JO, Klöcker N, Sailer CA, Bildl W, Biniossek M, Dehn D, Deller T, Eble S, Abbass K, Wangler T, Knaus HG, Fakler B (2006) The epilepsy-linked Lgil protein assembles into presynaptic Kv1 channels and inhibits inactivation by Kvbeta1. Neuron 49:697-706. CrossRef Medline

Senechal KR, Thaller C, Noebels JL (2005) ADPEAF mutations reduce levels of secreted LGI1, a putative tumor suppressor protein linked to epilepsy. Hum Mol Genet 14:1613-1620. CrossRef Medline

Steinlein OK (2004) Genetic mechanisms that underlie epilepsy. Nat Rev Neurosci 5:400-408. CrossRef Medline

Thomas R, Favell K, Morante-Redolat J, Pool M, Kent C, Wright M, Daignault K, Ferraro GB, Montcalm S, Durocher Y, Fournier A, Perez-Tur J, Barker PA (2010) LGI1 is a Nogo receptor 1 ligand that antagonizes myelin-based growth inhibition. J Neurosci 30:6607-6612. CrossRef Medline

Vincent A, Lang B, Kleopa KA (2006) Autoimmune channelopathies and related neurological disorders. Neuron 52:123-138. CrossRef Medline

Watanabe M, Fukaya M, Sakimura K, Manabe T, Mishina M, Inoue Y (1998) Selective scarcity of NMDA receptor channel subunits in the stratum lucidum (mossy fibre-recipient layer) of the mouse hippocampal CA3 subfield. Eur J Neurosci 10:478-487. CrossRef Medline

Yamasaki M, Matsui M, Watanabe M (2010) Preferential localization of muscarinic M1 receptor on dendritic shaft and spine of cortical pyramidal cells and its anatomical evidence for volume transmission. J Neurosci 30:4408-4418. CrossRef Medline

Yamasaki M, Miyazaki T, Azechi H, Abe M, Natsume R, Hagiwara T, Aiba A, Mishina M, Sakimura K, Watanabe M (2011) Glutamate receptor delta2 is essential for input pathway-dependent regulation of synaptic AMPAR contents in cerebellar Purkinje cells. J Neurosci 31:3362-3374. CrossRef Medline

Yamazaki M, Fukaya M, Hashimoto K, Yamasaki M, Tsujita M, Itakura M, Abe M, Natsume R, Takahashi M, Kano M, Sakimura K, Watanabe M (2010) TARPs gamma-2 and gamma-7 are essential for AMPA receptor expression in the cerebellum. Eur J Neurosci 31:2204-2220. CrossRef Medline

Yu YE, Wen L, Silva J, Li Z, Head K, Sossey-Alaoui K, Pao A, Mei L, Cowell JK (2010) Lgil null mutant mice exhibit myoclonic seizures and CA1 neuronal hyperexcitability. Hum Mol Genet 19:1702-1711. CrossRef Medline

Zhang JH, Chung TD, Oldenburg KR (1999) A Simple Statistical Parameter for Use in Evaluation and Validation of High Throughput Screening Assays. J Biomol Screen 4:67-73. CrossRef Medline

Zhou YD, Lee S, Jin Z, Wright M, Smith SE, Anderson MP (2009) Arrested maturation of excitatory synapses in autosomal dominant lateral temporal lobe epilepsy. Nat Med 15:1208-1214. CrossRef Medline 